\title{
1 Microbial Communities Performing Hydrogen Solventogenic Metabolism of Volatile Fatty Acids
}

$2 \quad{ }^{1,3}$ Gustavo Mockaitis*, ${ }^{1}$ Guillaume Bruant, ${ }^{2}$ Eugenio Foresti, ${ }^{2}$ Marcelo Zaiat, ${ }^{1}$ Serge R. Guiot.

$3 \quad{ }^{1}$ Anaerobic Technologies and Bioprocess Control group, Energy, Mining and Environment research

4 center, National Research Council Canada, 6100 Royalmount Avenue, H4P 2R2, Montreal, QC,

5 Canada.

$6 \quad{ }^{2}$ Biological Processes Laboratory, Center for Research, Development and Innovation in Environmental

7 Engineering, São Carlos School of Engineering, University of São Paulo (EESC/USP), Av. João

8 Dagnone, 1100, Santa Angelina, São Carlos, São Paulo 13563-120, Brazil.

$9{ }^{3}$ Interdisciplinary Research Group on Biotechnology Applied to the Agriculture and the Environment,

10 School of Agricultural Engineering, University of Campinas (GBMA/FEAGRI/UNICAMP), 501

11 Cândido Rondon Avenue, CEP, 13.083-875, Campinas, SP, Brazil.

Author

Gustavo Mockaitis

Guillaume Bruant

Eugenio Foresti

Marcelo Zaiat

Serge Roger Guiot

\section{ORCID}

0000-0002-4231-1056

0000-0002-8769-2868

0000-0002-7097-8990

0000-0001-7336-9093

0000-0002-2532-0620

12 (*Corresponding Author, gusmock@unicamp.br) 


\section{Abstract}

15 This work evaluates four different physicochemical pretreatments (acidic, thermal, acidic-thermal and 16 thermal-acidic) on an anaerobic inoculum used for alcohol production from acetate and butyrate. All 17 experiments were conducted in single batches using acetate and butyrate as substrates at $30{ }^{\circ} \mathrm{C}$ and 18 with a pressurized headspace of pure $\mathrm{H}_{2}$ at 2.15 atm (218.2 MPa). Thermal and acidic-thermal pretreatments lead to higher production of both ethanol and butanol. Mathematical modelling shows

that the highest attainable concentrations of ethanol and butanol produced were $122 \mathrm{mg} \mathrm{L}^{-1}$ and $97 \mathrm{mg}$

$21 \mathrm{~L}^{-1}$ for the thermal pretreatment (after 17.5 days) and $87 \mathrm{mg} \mathrm{L}^{-1}$ and $143 \mathrm{mg} \mathrm{L}^{-1}$ for the acidic-thermal 22 pretreatment (after 18.9 days). Acetate was produced in all assays. Thermodynamic data indicated that 23 a high $\mathrm{H}_{2}$ partial pressure favoured solventogenic metabolic pathways. Finally, sequencing data showed 24 that both thermal and acidic-thermal pretreatments selected mainly the bacterial genera Pseudomonas, Brevundimonas and Clostridium. The acidic-thermal pretreatment selected a bacterial community more adapted to the conversion of acetate and butyrate into ethanol and butanol, respectively. Thermal-acidic pretreatment was unstable, showing significant variability between replicates. Acidic pretreatment showed the lowest alcohol production.

\section{Keywords}

30 Anaerobic digestion, inoculum pretreatment, dark fermentation, alcohols, anaerobic microbiology

\section{Background}

32 The constant increase of prices of fossil fuels and the extensive land requirements for crop cultures targeting ethanol production is forcing the market to consider substitute avenues. The development of bioprocesses using organic residues as raw materials could be an alternative for fuel production. Anaerobic processes can be used to produce alcohol through solventogenic processes [1] and volatile 
into VFAs and $\mathrm{H}_{2}$ has an immediate commercial interest. Both propionic and butyric acids are raw materials of great interest, with many applications in various sectors, such as pharmaceutical and chemical industries [3]. $\mathrm{H}_{2}$ can be considered a raw material for subsequent processes and as an energy carrier to feed fuel cells [4].

Although anaerobic acidogenic processes could be used for wastes valorization, downstream processing of the VFAs obtained through those processes, such as bioconversion into their corresponding alcohols using $\mathrm{H}_{2}$ produced concomitantly, could have an even greater economic interest [5,6]. Ethanol and butanol produced through such processes can be used as drop-in liquid fuels, which have a higher market value per unit of energy. This two-steps approach (acidogenic followed by solventogenic processes) for ethanol and butanol production could both improve solvent production and reduce the toxicity linked to acidogenic processes products $[6,7]$.

The most important parameters influencing anaerobic solventogenic fermentations include $\mathrm{pH}$, organic acids, nutrient limitation, temperature, oxygen, and inoculum source $[1,6,8]$. Most of the studies performed on ethanol and butanol production through anaerobic solventogenic processes focussed on using sugars as carbon source and on using microbial pure cultures, with the most studied bacterial genera being Thermoanaerobacter, Thermoanaerobacterium and Caloramator under thermophilic conditions [9-13], and Clostridium [14-18].

Using mixed microbial cultures rather than pure cultures to produce alcohols from wastes through biological processes is of great interest. Mixed cultures increase process stability, improve the resistance to both toxicity and microbial contaminations, and bring higher substrate flexibility $[19,20]$. However, to date, there is still a lack of fundamental knowledge on mixed cultures used as inoculum, especially when $\mathrm{H}_{2}$ is used as an electron donor for the conversion of organic acids through solventogenic processes. Characterization of microbial communities capable of performing such processes is thus preponderant. 
61 Enhancement of microbial communities through pretreatment of the inoculum is an effective way to

62 induce changes in the communities to improve process performance. This approach has already been

63 successfully tested, but mainly for optimizing the acidogenic step in $\mathrm{H}_{2}$ production through dark

64 fermentation [21-23]. Pretreatments used in those studies consisted of modifications of the $\mathrm{pH}$ and

65 temperature applied to the inoculum. Since microbial communities involved in acidogenic processes

66 could use $\mathrm{H}_{2}$ as an electron donor to shift their metabolism to produce alcohols [1,5,24], the same

67 inoculum pretreatments could be applied to improve solventogenic processes.

68 The present work evaluated the effects of four pretreatments of a mixed microbial population (acidic,

69 thermal, acidic-thermal and thermal-acidic) on its capacity to convert VFAs into alcohols, using $\mathrm{H}_{2}$ as

70 electron donor and an equimolar mixture of acetate and butyrate as carbon sources. The composition

71 and dynamics of the mixed microbial community were analyzed.

\section{Materials and Methods}

\section{$73 \quad 4.1 \quad$ Medium}

74 The carbon source was an equimolar mixture of acetate and butyrate $\left(17 \mathrm{mmol} \mathrm{L}^{-1}\right.$, which correspond

75 to 1,000 and $1,476 \mathrm{mg} \mathrm{L}^{-1}$ of acetate and butyrate, respectively). The nutrient medium (micro and macro) composition was prepared considering previous work on anaerobic digestion microbiology [25]

77 and is described in Table 1. The initial $\mathrm{pH}$ was adjusted to 6.0.

78 Table 1 - Nutrients composition of the medium [25].

\begin{tabular}{lc|lc|lc}
\hline \multicolumn{1}{c}{ Nutrient } & Concentration & \multicolumn{1}{c|}{ Nutrient } & Concentration & \multicolumn{1}{c}{ Nutrient } & Concentration \\
\hline $\mathrm{NH}_{4} \mathrm{Cl}$ & $1 \mathrm{~g} \cdot \mathrm{L}^{-1}$ & $\mathrm{MnCl}_{2} \cdot 4 \mathrm{H}_{2} \mathrm{O}$ & $50 \mu \mathrm{g} \cdot \mathrm{L}^{-1}$ & $\left(\mathrm{NH}_{4}\right)_{6} \mathrm{Mo}_{7} \mathrm{O}_{24} \cdot 4 \mathrm{H}_{2} \mathrm{O}$ & $50 \mu \mathrm{g} \cdot \mathrm{L}^{-1}$ \\
$\mathrm{NaCl}$ & $100 \mathrm{mg} \cdot \mathrm{L}^{-1}$ & $\mathrm{AlCl}_{3}$ & $50 \mu \mathrm{g} \cdot \mathrm{L}^{-1}$ & Pyridoxine Chloride & $10 \mu \mathrm{g} \cdot \mathrm{L}^{-1}$ \\
$\mathrm{MgCl}_{2} \cdot 6 \mathrm{H}_{2} \mathrm{O}$ & $100 \mathrm{mg} \cdot \mathrm{L}^{-1}$ & $\mathrm{CoCl}_{2} \cdot 6 \mathrm{H}_{2} \mathrm{O}$ & $50 \mu \mathrm{g} \cdot \mathrm{L}^{-1}$ & $\mathrm{HCl} \mathrm{Concentrated}$ & $1 \mu \mathrm{L} \cdot \mathrm{L}^{-1}$ \\
$\mathrm{CaCl}_{2} \cdot 2 \mathrm{H}_{2} \mathrm{O}$ & $50 \mathrm{mg} \cdot \mathrm{L}^{-1}$ & $\mathrm{NiCl}_{2} \cdot 6 \mathrm{H}_{2} \mathrm{O}$ & $92 \mu \mathrm{g} \cdot \mathrm{L}^{-1}$ & $\mathrm{Na}_{2} \mathrm{SeO}_{3} \cdot 5 \mathrm{H}_{2} \mathrm{O}$ & $100 \mu \mathrm{g} \cdot \mathrm{L}^{-1}$
\end{tabular}




\begin{tabular}{lc|lc|lc}
$\mathrm{K}_{2} \mathrm{HPO}_{4} \cdot 3 \mathrm{H}_{2} \mathrm{O}$ & $400 \mathrm{mg} \cdot \mathrm{L}^{-1}$ & EDTA & $500 \mu \mathrm{g} \cdot \mathrm{L}^{-1}$ & Nicotinic acid & $5 \mu \mathrm{g} \cdot \mathrm{L}^{-1}$ \\
$\mathrm{FeCl}_{2} \cdot 4 \mathrm{H}_{2} \mathrm{O}$ & $2 \mathrm{mg} \cdot \mathrm{L}^{-1}$ & Biotin & $2 \mu \mathrm{g} \cdot \mathrm{L}^{-1}$ & Pantothenic acid & $5 \mu \mathrm{g} \cdot \mathrm{L}^{-1}$ \\
$\mathrm{H}_{3} \mathrm{BO}_{3}$ & $50 \mu \mathrm{g} \cdot \mathrm{L}^{-1}$ & Riboflavin & $5 \mu \mathrm{g} \cdot \mathrm{L}^{-1}$ & B & Vitamin \\
$\mathrm{ZnCl}_{2}$ & $50 \mu \mathrm{g} \cdot \mathrm{L}^{-1}$ & Thiamine & $5 \mu \mathrm{g} \cdot \mathrm{L}^{-1}$ & p-aminobenzoic acid & $5 \mu \mathrm{g} \cdot \mathrm{L}^{-1}$ \\
$\mathrm{CuCl}_{2} \cdot 2 \mathrm{H}_{2} \mathrm{O}$ & $38 \mu \mathrm{g} \cdot \mathrm{L}^{-1}$ & Folic acid & $2 \mu \mathrm{g} \cdot \mathrm{L}^{-1}$ & Thioctic acid & $5 \mu \mathrm{g} \cdot \mathrm{L}^{-1}$ \\
\hline
\end{tabular}

\subsection{Raw Inoculum}

81 The sludge used as raw inoculum in all assays was a primary digestate of the Carleton Corner Farms 82 (Marionville, ON, Canada - 45 $11^{\prime} 14.0^{\prime \prime} \mathrm{N} ; 7^{\circ} 21^{\prime} 54.1^{\prime \prime} \mathrm{W}$ ) collected in May 2013. The sludge was 83 sieved three times using a $2 \mathrm{~mm}$ mesh sieve to eliminate all inert and heterogeneous lignocellulosic 84 materials. The total volatile solids (TVS) content of the sieved sludge was $41 \pm 3 \mathrm{mg}$ TVS $\cdot \mathrm{L}^{-1}$. The sludge was centrifuged (SorvalTM RC 6 Plus, Thermo Inc.) for $40 \mathrm{~min}$ at $10 \mathrm{k} \mathrm{min}^{-1}$ and at $5^{\circ} \mathrm{C}$. The supernatant was discarded, and the pellet was resuspended in a phosphate buffer $\left(500 \mathrm{mg} \cdot \mathrm{L}^{-1} \mathrm{PO}_{4}{ }^{3-}\right)$,

87 using a homogenizer and disperser (Ultraturrax ${ }^{\mathrm{TM}} \mathrm{T} 25$, IKA Inc.) for $10 \mathrm{~min}$ at $15 \mathrm{k} \cdot \mathrm{min}^{-1}$. The sludge was then sonicated to disaggregate possible granules and biofilms, using a sonicator (Vibra Cell ${ }^{\mathrm{TM}}$ VC130, Sonics Inc.) with 30W of power. This step was repeated four times, on ice, with a time/volume dependence relation of $4 \mathrm{~s} \cdot \mathrm{mL}^{-1}$, with 2 minutes interval between sonications. These steps were carried

91 out to ensure the homogeneity of the inoculum and to wash possible organic dissolved materials

92 present in the sludge, which could be used as an alternative carbon source during the process. The $\mathrm{pH}$ 93 was corrected to 6.0 using a $1.0 \mathrm{M}$ solution of $\mathrm{HCl}$ under vigorous stirring. This processed sludge was 94 considered as the control inoculum.

\subsection{Pretreatments}

96 Four different physicochemical pretreatments - acidic, thermal, acidic-thermal, and thermal-acidic 97 were performed on the control inoculum. Pretreated inocula were then compared to each other, using 
the control inoculum as reference. All pretreated inocula were submitted to a starvation process to

reduce the length of the lag phase before inoculation. This step consisted of incubating the inoculum

100 for 72 hours at $30^{\circ} \mathrm{C}$, under stirring of $50 \mathrm{~min}^{-1}$. The control inoculum was submitted to the same starvation process and presented a TVS content of $31 \pm 0 \mathrm{mg}$ TVS $\cdot \mathrm{L}^{-1}$.

102 Acidic pretreatment consisted of decreasing the raw inoculum $\mathrm{pH}$ to 3.0 with a $12 \mathrm{M} \mathrm{HCl}$ solution

103 under continuous stirring, followed by an incubation of 24 hours at $30^{\circ} \mathrm{C}$, with stirring of $50 \mathrm{~min}^{-1} \cdot \mathrm{pH}$ was then increased to $6.0 \mathrm{using}$ a $2 \mathrm{M} \mathrm{NaOH}$ solution under stirring, followed by an incubation of 24 hours at $30^{\circ} \mathrm{C}$ under stirring of $50 \mathrm{~min}^{-1}$. In both $\mathrm{pH}$ decreasing and increasing inoculum, $\mathrm{pH}$ was controlled every hour for the five first hours of incubation to assure its stability. The acidic pretreated inoculum had a TVS of $29 \pm 1 \mathrm{mg}$ TVS $\cdot \mathrm{L}^{-1}$.

The thermal pretreatment consisted of heating the control inoculum at $90^{\circ} \mathrm{C}$ for 20 minutes, under 109 stirring and using a water batch. The inoculum was then immediately transferred to an ice batch until it 110 reached room temperature $\left(23^{\circ} \mathrm{C}\right)$. The thermally pretreated inoculum had a TVS of $31 \pm 0 \mathrm{mg} \mathrm{TVS} \cdot \mathrm{L}^{-}$ 1111.

112 The acidic-thermal and thermal-acidic pretreatments consisted of performing the two pretreatments 113 sequentially, as indicated by the pretreatment name. The second pretreatment was performed 114 immediately after the first one. The acidic-thermal pretreated inoculum had a TVS of $36 \pm 3 \mathrm{mg}$ $115 \mathrm{TVS} \cdot \mathrm{L}^{-1}$ and thermal-acidic pretreated inoculum had a TVS of $32 \pm 0 \mathrm{mg} \mathrm{TVS} \cdot \mathrm{L}^{-1}$.

\subsection{Experimental Setup}

117 Initial physicochemical parameters for each experiment (pretreatments and control) and initial 118 concentration of acetate, butyrate (before inoculation) and inoculum are shown in Table 2. Each 119 experiment was carried out in quintuplicates, using $538 \pm 3 \mathrm{~mL}$ sealed glass bottles, with an initial 
working volume of $110 \mathrm{~mL}$. All the bottles were incubated upside down to avoid any diffusion of $\mathrm{H}_{2}$

121 through the bottle's cap. All experiments were performed at $30^{\circ} \mathrm{C}$ under a $150 \mathrm{~min}^{-1} \mathrm{stirring}$. At the

122 beginning of each experiment, the headspace of each bottle was totally replaced by pure $\mathrm{H}_{2}(99.99 \%)$ at

123 a pressure of $2.39 \pm 0.08$ atm $(242.2 \pm 7.9 \mathrm{MPa})$. Such headspace replacement was repeated after each

124 sampling to ensure constant pressure and composition all along with the experiment.

125 Table 2 - Initial conditions (prior to inoculation) for each assay.

\begin{tabular}{l|cccccc}
\hline \multicolumn{1}{c|}{ Assay } & $\mathrm{pH}$ & $\begin{array}{c}\text { Acetate } \\
\mathrm{mg} \cdot \mathrm{L}^{-1}\end{array}$ & $\begin{array}{c}\text { Butyrate } \\
\mathrm{mg} \cdot \mathrm{L}^{-1}\end{array}$ & $\begin{array}{c}\text { Inoculum } \\
\mathrm{mg} \mathrm{TVS} \cdot \mathrm{L}^{-1}\end{array}$ & $\begin{array}{c}\text { Total } \mathrm{H}_{2} \\
\mathrm{mmol}\end{array}$ & $\begin{array}{c}\text { Dissolved } \mathrm{H}_{2}{ }^{*} \\
\mathrm{mmol} \cdot \mathrm{L}^{-1}\end{array}$ \\
\hline Control & 5.89 & 1153 & 1727 & $11.3 \pm 0.2(5)$ & $37.9 \pm 1.6(5)$ & 1.69 \\
Acidic & 5.94 & 1139 & 1708 & $11.0 \pm 0.2(5)$ & $39.2 \pm 0.2(5)$ & 1.74 \\
Thermal & 6.07 & 1143 & 1712 & $12.8 \pm 3.7(5)$ & $40.2 \pm 0.1(5)$ & 1.78 \\
Acidic-thermal & 5.84 & 1233 & 1846 & $12.7 \pm 0.2(5)$ & $40.8 \pm 0.2(5)$ & 1.81 \\
Thermal-acidic & 5.85 & 1213 & 1816 & $11.3 \pm 0.1(5)$ & $39.7 \pm 1.3(5)$ & 1.77 \\
\hline
\end{tabular}

126

Values in parenthesis are the number of replicates. * Dissolved $\mathrm{H}_{2}$ was estimated through Henry's Law [26,27].

127 Initial analyses of the liquid phase at the beginning of the essay confirmed the absence of significant 128 amounts of alcohols, mono or disaccharides, and fatty acids other than acetate and butyrate.

$129 \quad 4.5 \quad$ Physicochemical Analyses

130 pH monitoring was performed with a portable potentiometer (Accumet ${ }^{\mathrm{TM}}$ AP115, Fisher Scientific ${ }^{\mathrm{TM}}$ ),

131 with a microprobe electrode $\left(\right.$ Accumet $^{\mathrm{TM}} 55500-40$, Cole Parmer ${ }^{\mathrm{TM}}$ ), using the method $4500-\mathrm{H}^{+} \mathrm{B}$,

132 described by APHA [28]. TVS analyses were performed in quintuplicate, following method 2540-E,

133 accordingly to APHA [28]. The pressure inside the bottles was measured using a digital manometer

134 (DM8200, General Tools \& Instruments $\left.{ }^{\mathrm{TM}}\right)$ with a range pressure of $0-6,804$ atm $(0-689.5 \mathrm{MPa})$.

135 Dissolved $\mathrm{CO}_{2}$ was measured through alkalinity determination by potentiometric titration [29,30].

136 Mono, disaccharides, and organic fatty acids were analyzed using a Waters ${ }^{\mathrm{TM}}$ HPLC, which consisted 137 of a pump (model 600) and an autosampler (model 717 Plus). The system was equipped with a 
138 refractive index detector (model 2414) for mono and disaccharides analyses. Organics acids were

139 monitored from the same samples using the same equipment through a linked photodiode array detector

140 (model 2996). A Transgenomic ${ }^{\mathrm{TM}}$ ICSep IC-ION-300 (300 mm x $7.8 \mathrm{~mm}$ outer diameter) column was

141 used to separate all compounds and was operated at $35^{\circ} \mathrm{C}$. The mobile phase was $0.01 \mathrm{~N} \mathrm{H}_{2} \mathrm{SO}_{4}$ at 0.4

$142 \mathrm{~mL} \mathrm{~min}^{-1}$ under an isocratic flow.

143 Alcohols (methanol, ethanol, acetone, 2-propanol, tert-butanol, n-propanol, sec-butanol, and n-butanol)

144 were measured on an Agilent $^{\mathrm{TM}} 6890$ gas chromatograph (GC) equipped with a flame ionization 145 detector [31].

$146100 \mu \mathrm{L}$ gas samples, obtained using a gas-tight syringe (model 1750, Hamilton ${ }^{\mathrm{TM}}$ ), were used for gas

147 composition $\left(\mathrm{H}_{2}, \mathrm{CO}_{2}, \mathrm{CH}_{4}\right.$ and $\mathrm{N}_{2}$ ) measurements with a GC (HP 6890, Hewlett Packard ${ }^{\mathrm{TM}}$ ) equipped

148 with a thermal conductivity detector (TCD) and an $11 \mathrm{~m} \mathrm{x} 3.2 \mathrm{~mm} \mathrm{60/80} \mathrm{mesh} \mathrm{packed} \mathrm{column}$

149 (Chromosorb $^{\mathrm{TM}}$ 102, Supelco $\left.{ }^{\mathrm{TM}}\right)$. The column temperature was held at $50^{\circ} \mathrm{C}$ for the entire run (4 min).

150 The carrier gas was argon. The injector and detector were maintained at $125^{\circ} \mathrm{C}$ and $150^{\circ} \mathrm{C}$, 151 respectively.

1524.6 16S rRNA gene Sequencing and microbial characterization

153 Bacterial 16S rRNA genes (V2 region) were amplified using the set of primers 16S-F343 IonA L01

$154 \quad\left(343-357 ; \quad 5^{\prime} \quad\right.$ TACGGRAGGCAGCAG $\left.\quad 3^{\prime}\right) \quad$ and $\quad$ 16S-R533 Ion P1 (516-533; 5'

155 ATTACCGCGGCTGCTGGC 3') [32]. A sample-specific multiplex identifier was added to each

156 forward primer and an Ion Torrent adapter to each primer. DNA extraction was conducted [33]. DNA

157 was then purified [34,35]. Amplification reactions were performed in a final volume of $20 \mu \mathrm{L}$, which

158 contained $1 \mu \mathrm{L}$ of DNA, $0.5 \mu \mathrm{M}$ of each primer, $7.5 \mu \mathrm{L}$ of RNAse free $\mathrm{H}_{2} \mathrm{O}$ and $10 \mu \mathrm{L}$ of $2 \mathrm{X}$

159 HotStarTaq $^{\mathrm{TM}}$ Plus Master Mix (HotStarTaq ${ }^{\mathrm{TM}}$ Plus Master Mix Kit, Qiagen, USA). PCR conditions

160 were an initial denaturation of $5 \mathrm{~min}$ at $95^{\circ} \mathrm{C}$ followed by 25 cycles of $30 \mathrm{~s}$ at $95^{\circ} \mathrm{C}, 30 \mathrm{~s}$ at $55^{\circ} \mathrm{C}$, and 
$16145 \mathrm{~s}$ at $72^{\circ} \mathrm{C}$, with a final elongation step of $10 \mathrm{~min}$ at $72^{\circ} \mathrm{C}$. PCR products were purified and quantified

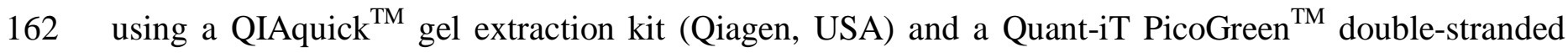

163 DNA quantitation kit (Life Technologies Inc., USA) according to manufacturer's instructions. The

164 pooled amplicons were then sequenced using the Ion TorrentTM (Life Technologies Inc., USA)

165 sequencing platform with a 314 chip. Bacterial 16S rRNA gene sequences generated were and analyzed

166 using the ribosomal database project (RDP) classifier [36], using a bootstrap confidence cutoff of 50\%,

167 as recommended by RDP classifier [37] for short sequences (less than $250 \mathrm{bp}$ ). Before analysis,

168 sequences shorter than 75 bp and sequences with unidentified bases $(\mathrm{N})$ were removed.

169

\subsection{Kinetics}

170 Kinetic parameters for ethanol and butanol production were calculated using a modified Boltzmann

171 sigmoidal model, as shown by Equation 1. The model was modified to incorporate parameter $r_{\text {max }}$ as

172 the maximum rate of the process $\left(\mathrm{mg} \mathrm{L}^{-1} \mathrm{~d}^{-1}\right)$.

$$
C(t)=C_{\max }-\frac{C_{\max }}{1+e^{\left(\frac{4 \cdot r_{\max }\left(t-t_{m}\right)}{C_{\max }}\right)}} \quad \text { Equation 1 }
$$

173

174 Where $C(t)$ is the function of concentration in respect of time $\left(\mathrm{mg} \mathrm{L}^{-1}\right), t$ is time (d), $C_{\max }$ is the

175 maximum concentration reached $\left(\mathrm{mg} \mathrm{L}^{-1}\right)$, and $t_{m}$ is the value of time when $\frac{d C\left(t_{m}\right)}{d t}=r_{\max }(\mathrm{d})$.

176 From some of the calculated parameters showed in Equation 1, is possible to calculate the length of

177 both lag $\left(t_{i}, \mathrm{~d}\right)$ and exponential $\left(t_{e}, \mathrm{~d}\right)$ phases, as depicted in Equation 3 and 4, respectively.

$$
\begin{array}{ll}
t_{i}=t_{m}-\frac{C_{\max }}{2 \cdot r_{\max }} & \text { Equation } 3
\end{array}
$$




$$
t_{e}=\frac{C_{\max }}{r_{\max }} \quad \text { Equation } 4
$$

179 All fittings were performed using the software Microcal Origin Pro $^{\mathrm{TM}}$ 9.0, using a Levenberg-

180 Marquardt algorithm for fitting and initializing the equations parameters.

\subsection{Metabolisms' Gibb's free energy}

182 Gibb's free energy values were calculated for all pathways depicted in Figure 1, except for pathway 1,

183 for both initial $\left(\Delta \mathrm{G}_{\mathrm{r}}^{\mathrm{I}}\right)$ and final $\left(\Delta \mathrm{G}_{\mathrm{r}}^{\mathrm{F}}\right)$ conditions and were compared with the free energy for standard

184 conditions $\left(\Delta \mathrm{G}_{\mathrm{r}}^{\mathrm{o}}\right) . \Delta \mathrm{G}_{\mathrm{r}}^{\mathrm{o}}$ values for each reaction were estimated [38,39], considering 1 mol of each

185 product and reagent at STP. $\Delta \mathrm{G}_{\mathrm{r}}^{\mathrm{I}}$ and $\Delta \mathrm{G}_{\mathrm{r}}^{\mathrm{F}}$ values were calculated using the Nernst equation at $30^{\circ} \mathrm{C}$

186 and considered the concentrations of the metabolites presented in Table 4. To make all calculations

187 possible, compounds that were not detected through the experiments, such as butanol, propionate,

188 propanol, and ethanol, were assumed to be present, but at the same concentration of their respective

189 lower detection limit for each methodology. This represents $10^{-3} \mathrm{mmol} \mathrm{L}^{-1}$ for volatile acids and 190 alcohols and $10^{-1} \mathrm{mmol} \mathrm{L}^{-1}$ for $\mathrm{CO}_{2}$.

\section{Results and Discussion}

\section{$192 \quad 5.1 \quad$ Metabolic Model and Molar Balances}

193 For all experiments, gas composition of the headspace was monitored prior to its replacement and $\mathrm{H}_{2}$

194 pressure was constantly kept at $2.15 \pm 0.10$ atm. $\mathrm{H}_{2}$ was the sole gas detected in the headspace in all

195 cases, except for the control experiment, which showed a methane production of $0.24 \mathrm{mmol}(5.37 \mathrm{~mL}$

196 at standard temperature and pressure (STP)). Initial and final concentrations of the main metabolites 
197 (added or produced) and of dissolved $\mathrm{H}_{2}$ and $\mathrm{CO}_{2}$ are presented in Table 3. Dissolved $\mathrm{H}_{2}$ was not

198 measured but estimated through Henry's law [26,27], and its concentration was considered constant,

199 due to its continuous replacement. Dissolved $\mathrm{CO}_{2}$ was calculated from the alkalinity value measured at 200 the beginning of each assay. $\mathrm{CO}_{2}, \mathrm{O}_{2}$ and $\mathrm{N}_{2}$ were never detected at the headspace. Acetone, lactate, 201 and methanol were only sporadically detected in the liquid phase, in traces concentrations (below $1 \mathrm{mg}$ $202 \mathrm{~L}^{-1}$ ). Neither propionate nor alcohols were detected at the beginning of each experiment. 
Table 3 - Mean concentrations of all metabolites detected and of dissolved $\mathrm{H}_{2}$ and $\mathrm{CO}_{2}$.

\begin{tabular}{|c|c|c|c|c|c|c|c|c|c|c|}
\hline \multirow{3}{*}{ Metabolite $^{\mathrm{a}}$} & \multicolumn{10}{|c|}{ Concentration $\left(\mathrm{mg} \mathrm{L}^{-1}\right)$} \\
\hline & \multicolumn{2}{|c|}{ Control } & \multicolumn{2}{|c|}{ Acidic } & \multicolumn{2}{|c|}{ Thermal } & \multicolumn{2}{|c|}{ Acidic-thermal } & \multicolumn{2}{|c|}{ Thermal-acidic } \\
\hline & Initial & Final & Initial & Final & Initial & Final & Initial & Final & Initial & Final \\
\hline Acetate & $1225 \pm 1$ & $1575 \pm 40$ & $1222 \pm 3$ & $1492 \pm 24$ & $1206 \pm 2$ & $\begin{array}{c}1722 \pm \\
120\end{array}$ & $1235 \pm 3$ & $1645 \pm 44$ & $1224 \pm 2$ & $1447 \pm 26$ \\
\hline Butyrate & $1831 \pm 3$ & $1773 \pm 24$ & $1828 \pm 1$ & $1935 \pm 14$ & $1791 \pm 4$ & $1796 \pm 17$ & $1840 \pm 5$ & $1664 \pm 25$ & $1831 \pm 4$ & $1738 \pm 58$ \\
\hline Propionate & - & $42 \pm 12$ & - & $35 \pm 4$ & - & $107 \pm 25$ & - & $52.8 \pm 9.2$ & - & $40.1 \pm 5.4$ \\
\hline Ethanol & - & $40 \pm 6$ & - & $14 \pm 2$ & - & $104 \pm 7$ & - & $94 \pm 9$ & - & $33 \pm 6$ \\
\hline Propanol & - & - & - & $0.3 \pm 0.2$ & - & - & - & $1.8 \pm 0.1$ & - & $1.0 \pm 0.3$ \\
\hline Butanol & - & $49 \pm 8$ & - & $11 \pm 2$ & - & $83 \pm 3$ & - & $154 \pm 14$ & - & $61 \pm 25$ \\
\hline Dissolved $\mathrm{H}_{2}$ & \multicolumn{2}{|c|}{$1.6 \pm 0.1$} & \multicolumn{2}{|c|}{$1.7 \pm 0.0$} & \multicolumn{2}{|c|}{$1.6 \pm 0.1$} & \multicolumn{2}{|c|}{$1.7 \pm 0.1$} & \multicolumn{2}{|c|}{$1.7 \pm 0.1$} \\
\hline Dissolved $\mathrm{CO}_{2}$ & 3.07 & - & 2.40 & - & 3.30 & - & 1.56 & - & 2.19 & - \\
\hline Duration (d) & \multicolumn{2}{|c|}{29.2} & \multicolumn{2}{|c|}{29.1} & \multicolumn{2}{|c|}{29.1} & \multicolumn{2}{|c|}{29.1} & \multicolumn{2}{|c|}{29.0} \\
\hline
\end{tabular}

${ }^{a}$ All values are expressed in $\mathrm{mg} \mathrm{L}^{-1}$ except for dissolved $\mathrm{H}_{2}$ and $\mathrm{CO}_{2}$ expressed in $\mathrm{mmol} \mathrm{L}^{-1}$. Mean concentrations of all volatile acids and alcohols was calculated considering 5 replicates. The amount of $\mathrm{H}_{2}$ was kept 
208 Acetate and butyrate concentrations along the process demonstrated acetate production in all cases. 209 Only minor variations of butyrate concentrations (slight decrease for the control and the acidic-thermal 210 and thermal-acidic pretreatments, low production for the acidic and the thermal pretreatments) were 211 observed. Such results suggested an alternative organic matter input in the system. This hypothesis is 212 consistent with the decrease of the concentration of total volatile solids (TVS) that was observed for all 213 conditions tested, as a direct effect of the different pretreatments on the biomass, which might have 214 resulted in partial microbial cell death. Such non-living cells constituted non-soluble organic matter 215 which was probably hydrolyzed and then consumed as a supplementary carbon source. Based on well216 known anaerobic acidogenic and solventogenic metabolisms [1,24], and considering the inoculum as 217 the only possible alternative source of organic matter, an alternative metabolic model including this 218 alternative contribution and considering the metabolites (added and produced) presented in Table 3, 219 was developed, as shown in Figure 1.

220 Figure 1 depicts butanol as the only product from lysed inoculum (pathway 1). Pathway 1 seems the 221 only way to explain butanol production maintaining the butyric acid concentration constant since it is 222 thermodynamically unfeasible to form butanol from acetate. Acetate could only be produced from 223 butyrate, considering the high concentration of hydrogen and lack of $\mathrm{CO}_{2}$ in all assays, indicating that 224 acetate was produced through acetogenesis from butyrate (pathway 2) or homoacetogenesis (pathway 225 7) after initial dissolved $\mathrm{CO}_{2}$ was consumed. 


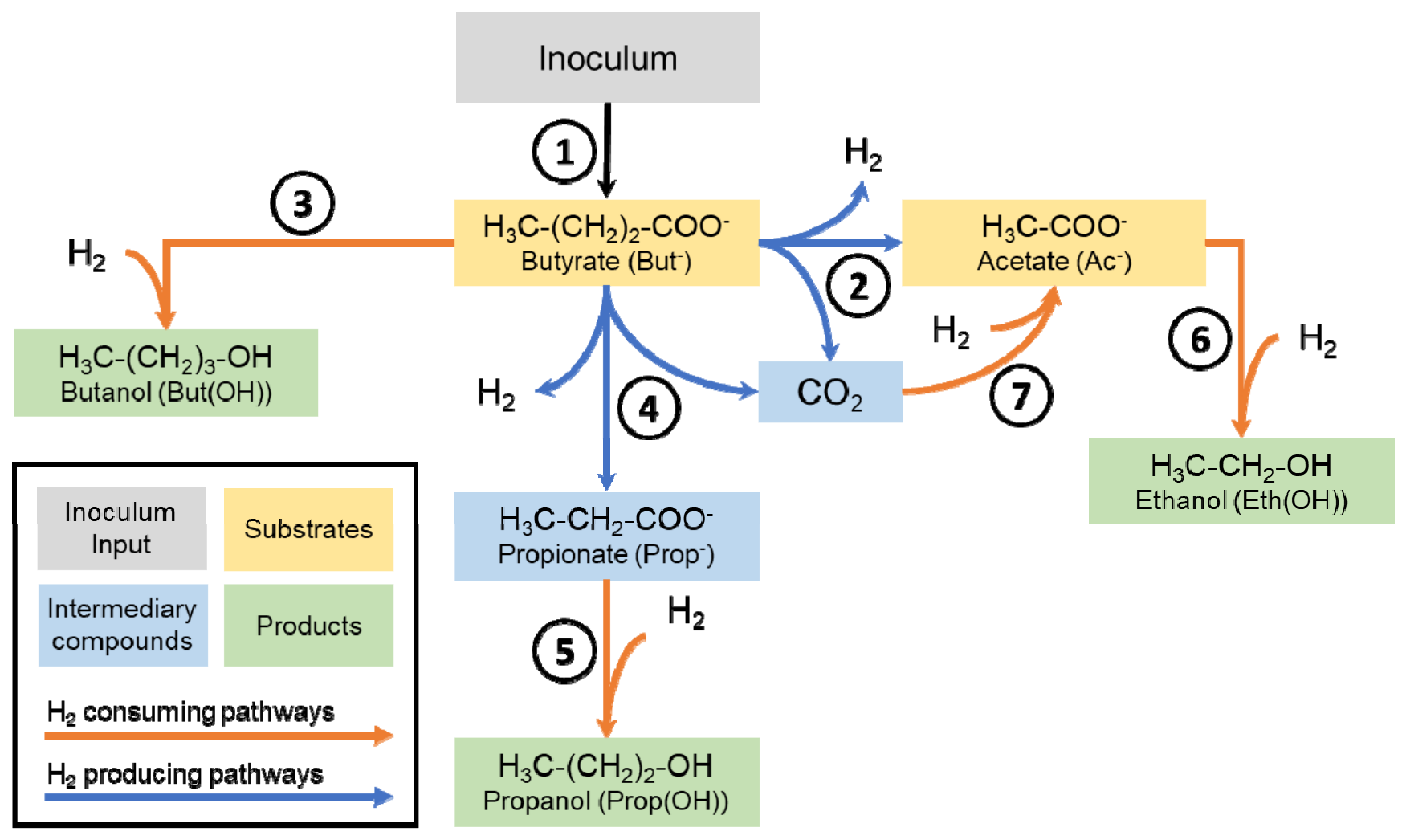

\section{Metabolic Pathways}

\section{(1) Organic matter in the inoculum to butyrate}

(2) Acetogenesis from butyrate

(3) Solventogenesis from butyrate to butanol

(4) Acidogenesis from butyrate to propionate

(5) Solventogenesis from propionate to propanol

6 Solventogenesis from acetate to ethanol

\section{(7) Homoacetogenesis}

$$
\begin{array}{r}
\text { But }+4 \mathrm{H}_{2} \mathrm{O} \rightarrow \mathrm{AC}^{-}+2 \mathrm{CO}_{2}+6 \mathrm{H}_{2} \\
\text { But }+\mathrm{H}^{+}+2 \mathrm{H}_{2} \rightarrow \text { But }(\mathrm{OH})+\mathrm{H}_{2} \mathrm{O} \\
\text { But }+2 \mathrm{H}_{2} \mathrm{O} \rightarrow \text { Prop }^{-}+\mathrm{CO}_{2}+3 \mathrm{H}_{2} \\
\text { Prop }+\mathrm{H}^{+}+2 \mathrm{H}_{2} \rightarrow \text { Prop }(\mathrm{OH})+\mathrm{H}_{2} \mathrm{O} \\
\text { Ac }+\mathrm{H}^{+}+2 \mathrm{H}_{2} \rightarrow \text { Eth }(\mathrm{OH})+\mathrm{H}_{2} \mathrm{O} \\
2 \mathrm{CO}_{2}+4 \mathrm{H}_{2} \rightarrow \text { AC }^{-}+\mathrm{H}^{+}+2 \mathrm{H}_{2} \mathrm{O}
\end{array}
$$

Figure 1 - Alternative metabolic model proposed for the solventogenic process using butyrate and acetate as substrates. Pathways in orange are exergonic; pathways in blue are endergonic $\left(\right.$ at $30^{\circ} \mathrm{C}, \mathrm{pH}$ of 6.0, with a constant $\mathrm{CO}_{2}$ concentration of $10^{-3} \mathrm{mmol} \mathrm{L}^{-1}$, in initial conditions as depicted in Table 3). The metabolic model depicted in Figure 1 was used to perform a molar balance of all carbon inputs and outputs during the process (Table 4) and estimates the butyrate input from inoculum. All balances were performed on a $1 \mathrm{~L}$ basis and derived from initial and final experimental values obtained in all 
conditions (Table 3), except for the organic matter from the inoculum (pathway 1) which was 234 expressed in butyrate equivalent.

235 Table 4 - Molar balance of all metabolites detected in all metabolic pathways of each experiment.

\begin{tabular}{|c|c|c|c|c|c|c|}
\hline \multirow{2}{*}{ Metabolite } & \multirow{2}{*}{ Pathway $^{\mathrm{a}}$} & \multicolumn{5}{|c|}{ Molar Balance $(\mathrm{mmol})^{\mathrm{b}}$} \\
\hline & & Control & Acidic & Thermal & Acidic-thermal & Thermal-acidic \\
\hline \multirow{6}{*}{ Butyrate } & Initial $^{*}$ & 21.0 & 21.0 & 20.6 & 21.1 & 21.0 \\
\hline & Final $^{*}$ & 20.4 & 22.2 & 20.6 & 19.1 & 20.0 \\
\hline & 1 & +3.16 & +3.56 & +6.92 & +4.73 & +1.96 \\
\hline & 2 & -2.53 & -1.73 & -4.34 & -3.92 & -1.57 \\
\hline & 3 & -0.66 & -0.15 & -1.12 & -2.08 & -0.82 \\
\hline & 4 & -0.57 & -0.48 & -1.46 & -0.75 & -0.57 \\
\hline Butanol & $3^{*}$ & +0.66 & +0.15 & +1.12 & +2.08 & +0.82 \\
\hline \multirow{2}{*}{ Propionate } & $4^{*}$ & +0.57 & +0.48 & +1.46 & +0.75 & +0.57 \\
\hline & 5 & - & - & - & -0.03 & -0.02 \\
\hline Propanol & $5^{*}$ & - & - & - & +0.03 & +0.02 \\
\hline \multirow{5}{*}{ Acetate } & Initial $^{*}$ & 20.7 & 20.7 & 20.4 & 20.9 & 20.7 \\
\hline & Final $^{*}$ & 26.7 & 25.3 & 29.2 & 27.9 & 24.5 \\
\hline & 2 & +2.53 & +1.73 & +4.34 & +3.92 & +1.57 \\
\hline & 6 & -0.87 & -0.30 & -2.26 & -2.04 & -0.72 \\
\hline & 7 & +4.35 & +3.17 & +6.72 & +5.08 & +2.95 \\
\hline Ethanol & $6^{*}$ & +0.87 & +0.30 & +2.26 & +2.04 & +0.72 \\
\hline \multirow{4}{*}{ Dissolved $\mathrm{CO}_{2}$} & Initial* & 3.07 & 2.40 & 3.30 & 1.56 & 2.19 \\
\hline & 2 & +5.05 & +3.46 & +8.68 & +7.85 & +3.14 \\
\hline & 4 & +0.57 & +0.48 & +1.46 & +0.75 & +0.57 \\
\hline & 7 & -8.69 & -6.34 & -13.4 & -10.2 & -5.90 \\
\hline
\end{tabular}

*Values obtained experimentally (derived from initial and final concentrations as indicated in Table 3).

$237 \quad$ aetabolic pathways described in Figure 1.

238 bBalance on a $1 \mathrm{~L}$ basis; "+" indicates a production; "-" indicates a consumption.

240 According to the mass balance shown in Table 4, $\mathrm{CO}_{2}$ was produced by converting butyrate into 241 acetate (pathway 2) and by acidogenesis from butyrate to propionate (pathway 4). This $\mathrm{CO}_{2}$ was then 242 consumed to form acetate through a homoacetogenic pathway (pathway 7). This hypothesis was 
243 supported by the absence of gaseous $\mathrm{CO}_{2}$ in all experiments, followed by an increase in acetate 244 concentration. This $\mathrm{CO}_{2}$ absence may be linked to microbial communities more adapted to convert 245 butyrate and $\mathrm{CO}_{2}$ into acetate (pathways 2 and 7, respectively) rather than to the conversion of acetate 246 into ethanol (pathway 6). This metabolic model also indicates that butyrate was mainly consumed to 247 produce acetate (pathway 2) in all studied conditions and the organic matter from the inoculum 248 (pathway 1) represented an external input since butyrate concentrations were almost constant in all 249 assays, although consumed to form butanol (pathway 3). Ethanol and butanol were produced (pathways 2503 and 6) in all experiments. These pathways were more active in the experiments with thermal and 251 acidic-thermal pretreatments, as these conditions showed the highest ethanol and butanol production 252 among all other experiments. Although acidogenesis from butyrate to propionate (pathway 4) was 253 active in all conditions, conversion of propionate into propanol (pathway 5) was not an important 254 metabolic pathway. Propanol production was not expressive in neither experiments since it showed the 255 highest concentration of $1.82 \mathrm{mg} \mathrm{L}^{-1}$ in acidic-thermal pretreatment essay.

256 The successful closure of molar balances shown in Table 4, with a stoichiometrically balanced sum of 257 all inputs and outputs (considering the contribution of the inoculum), indicates that the metabolic 258 model proposed in Figure 1 accurately represents the solventogenic processes occurring in all studied 259 conditions. An energy balance based on the mass balance depicted in Table 4 was calculated to 260 estimate Gibb's free energy values for each pathway for both initial and final conditions (Figure 2). 261 Those values provide an overview of the thermodynamic feasibility of each pathway involved in the 262 solventogenic process and tend to validate the metabolism proposed in Figure 1. 


\begin{tabular}{|c|c|c|c|c|c|c|c|c|c|c|c|}
\hline \multirow{3}{*}{ 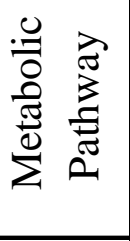 } & \multicolumn{11}{|c|}{ Metabolism Free Energy $\left(\mathrm{kJ} \mathrm{mol}^{-1}\right)$} \\
\hline & \multirow{2}{*}{$\Delta \mathrm{G}_{\mathrm{r}}^{\mathrm{o}}$} & \multicolumn{2}{|c|}{ Control } & \multicolumn{2}{|c|}{ Acidic } & \multicolumn{2}{|c|}{ Thermal } & \multicolumn{2}{|c|}{ Acidic-thermal } & \multicolumn{2}{|c|}{ Thermal-acidic } \\
\hline & & $\Delta \mathrm{G}_{\mathrm{r}}^{\mathrm{I}}$ & $\Delta \mathrm{G}_{\mathrm{r}}^{\mathrm{F}}$ & $\Delta \mathrm{G}_{\mathrm{r}}^{\mathrm{I}}$ & $\Delta \mathrm{G}_{\mathrm{r}}^{\mathrm{F}}$ & $\Delta \mathrm{G}_{\mathrm{r}}^{\mathrm{I}}$ & $\Delta \mathrm{G}_{\mathrm{r}}^{\mathrm{F}}$ & $\Delta \mathrm{G}_{\mathrm{r}}^{\mathrm{I}}$ & $\Delta \mathrm{G}_{\mathrm{r}}^{\mathrm{F}}$ & $\Delta \mathrm{G}_{\mathrm{r}}^{\mathrm{I}}$ & $\Delta \mathrm{G}_{\mathrm{r}}^{\mathrm{F}}$ \\
\hline 2 & 109 & 234 & -158 & 221 & -162 & 237 & -156 & 200 & -156 & 217 & -160 \\
\hline 3 & $-20,6$ & -291 & -129 & -291 & -168 & -290 & -116 & -291 & -99 & -291 & -123 \\
\hline 4 & 55,7 & -129 & -170 & -135 & -177 & -127 & -147 & -146 & -163 & -138 & -171 \\
\hline 5 & $-24,4$ & -47 & -205 & -47 & -201 & -47 & -228 & -47 & -125 & -47 & -135 \\
\hline 6 & $-20,5$ & -290 & -129 & -290 & -154 & -290 & -107 & -291 & -109 & -290 & -131 \\
\hline 7 & -40 & -67 & 339 & -54 & 337 & -70 & 341 & -33 & 340 & -50 & 337 \\
\hline
\end{tabular}

\begin{tabular}{|c|c|c|c|}
\hline-400 & Exergonic & Endergonic & 400 \\
\hline
\end{tabular}

265 Figure 2 - Gibbs' free energy for initial $\left(\Delta \mathrm{G}_{\mathrm{r}}^{\mathrm{I}}\right)$, final $\left(\Delta \mathrm{G}_{\mathrm{r}}^{\mathrm{F}}\right)$ and standard $\left(\Delta \mathrm{G}_{\mathrm{r}}^{\mathrm{o}}\right)$ conditions for each 266 pathway (as defined in Figure 1) in each experiment. Greenish values $(<0)$ are exergonic and reddish 267 values (>0) are endergonic.

Energetic profiles could help to anticipate changes within metabolic pathways. As shown in Figure 2, the estimated $\Delta \mathrm{G}_{\mathrm{r}}^{\mathrm{o}}$ values indicate that acetogenesis from butyrate and acidogenesis from butyrate to

271 propionate (pathways 2 and 4, respectively) are theoretically thermodynamically unfeasible 272 metabolisms. Nevertheless, these pathways became thermodynamically feasible due to the absence (or 273 low concentration) of dissolved $\mathrm{CO}_{2}$ at the course of each essay. Acetogenesis from butyrate (pathway 274 2) was likely inhibited at the beginning of each experiment due to the concentration of $\mathrm{H}_{2}$ and $\mathrm{CO}_{2}$. 275 During the experiment, $\mathrm{CO}_{2}$ was progressively consumed through homoacetogenesis (pathway 7), 276 which rendered pathway 2 thermodynamically feasible. At low concentrations of $\mathrm{CO}_{2}$ as found after 277 the beginning of each essay, the homoacetogenic pathway might have become thermodynamically 278 unfeasible. Gibb's free energy values found for these pathways could explain the production of acetate 279 observed in all studied conditions, all along the process. Metabolic pathways 3 (solventogenesis from 280 butyrate to butanol) and 6 (solventogenesis from acetate to ethanol) were thermodynamically feasible 
in all studied conditions all along the process, explaining the observed production of such alcohols.

Metabolic pathway 4 (acidogenesis from butyrate to propionate) was unfeasible at the ending of each

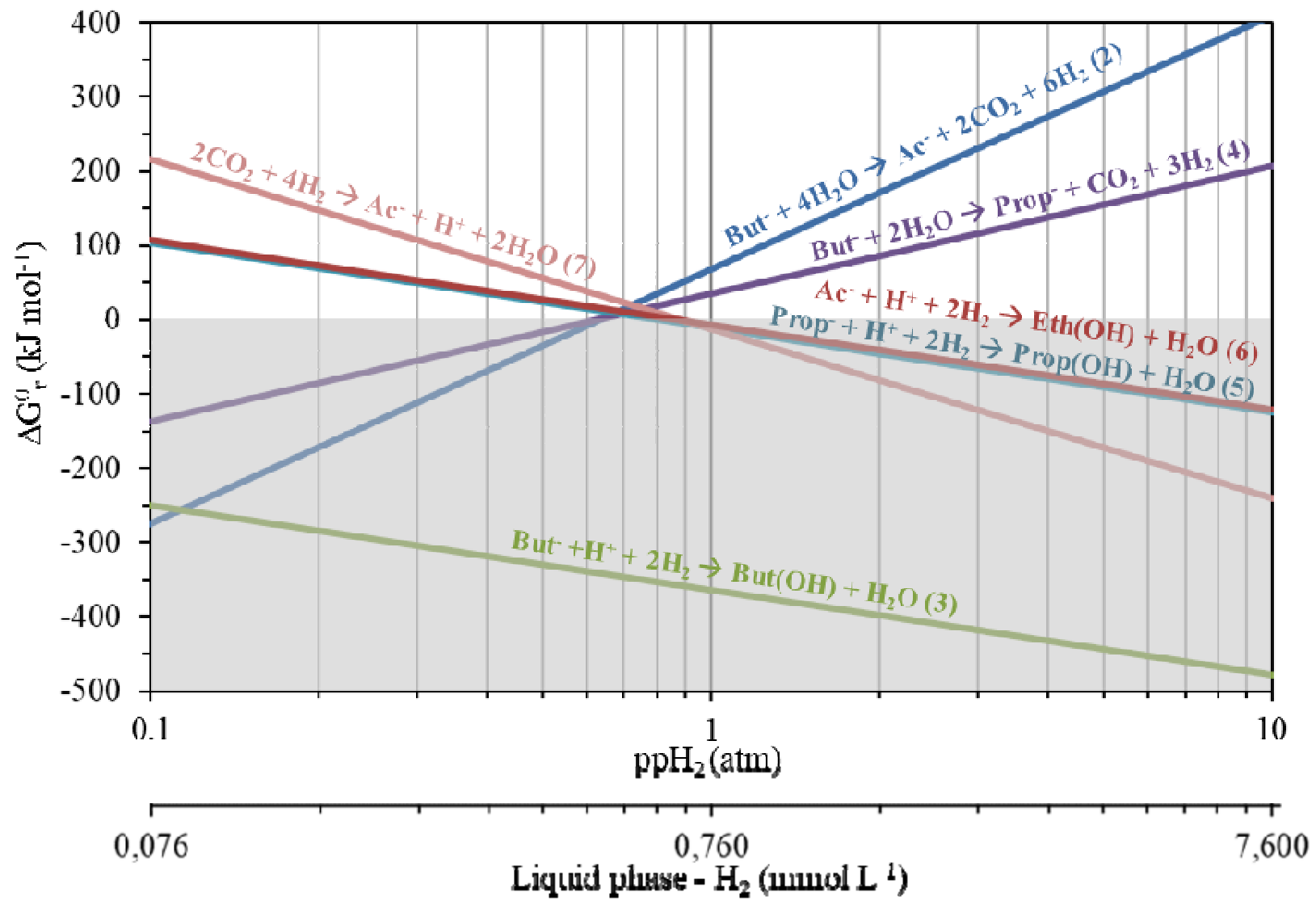

286 Figure 3 - Evolution of the standard Gibbs' free energy $\left(\Delta \mathrm{G}_{\mathrm{r}}^{\mathrm{o}}\right)$ in function of the partial pressure of $\mathrm{H}_{2}$. 287 Evolution for each metabolic pathway (as defined in Figure 1), at $30{ }^{\circ} \mathrm{C}$, and with a standard

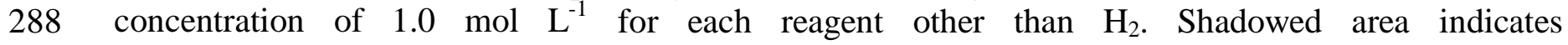
289 thermodynamically feasible reactions.

As described previously, $\mathrm{H}_{2}$ has a significant role as a co-substrate in the anaerobic process energetics [40,41]. As shown in Figure 3, solventogenesis of butanol from butyrate (pathway 3) is less sensitive to low $\mathrm{pp}_{\mathrm{H}_{2}}$ than solventogenesis of ethanol and propanol, respectively from acetate (pathway 6) and propionate (pathway 5). By extrapolation, equilibrium $\left(\Delta \mathrm{G}_{\mathrm{r}}^{\mathrm{o}}=0\right)$ in pathway 3 would be achieved at a 
$295 \mathrm{pp}_{\mathrm{H}_{2}}$ of $4 \cdot 10^{-4}$ atm (43.7 Pa), implying that solventogenesis of butanol could theoretically be carried 296 out at very low $\mathrm{pp}_{\mathrm{H}_{2}}$. It is also possible to infer from Figure 3 that at $\mathrm{pp}_{\mathrm{H}_{2}}$ higher than 0.62 atm 297 (62.5 MPa), acidogenesis of propionate (pathway 4) and acetogenesis of acetate (pathway 2) from 298 butyrate will stop, shutting down the production of acetate, propionate and $\mathrm{H}_{2}$. In addition to low $\mathrm{CO}_{2}$ 299 concentrations, high $\mathrm{pp}_{\mathrm{H}_{2}}$ thus represents an important factor that renders such process 300 thermodynamically feasible and favours solventogenesis from VFAs.

\subsection{Alcohols and VFAs metabolisms}

302 As shown in Figure 4, the highest concentrations of alcohols were obtained for both thermal and acidic303 thermal pretreatments, with the best rate observed for the acidic-thermal pretreatment, especially for 304 butanol production. On the opposite, the lowest alcohol production was observed for the acidic 305 pretreatment. Acetate and butyrate concentrations along the essays confirmed the contribution of the 306 inoculum as an important source of organic matter as the substrate for alcohol production, since in all 307 conditions tested, acetate concentration increased, and butyrate concentration increased or only slightly 308 decreased. These results reinforced the hypothesis described in Figure 1 and Table 4 of an acetate 309 production through acetogenesis of butyrate (pathway 2) and homoacetogenesis (pathway 7), and 310 preferentially through pathway 2 due to low concentrations of $\mathrm{CO}_{2}$ at the beginning of all assays. 


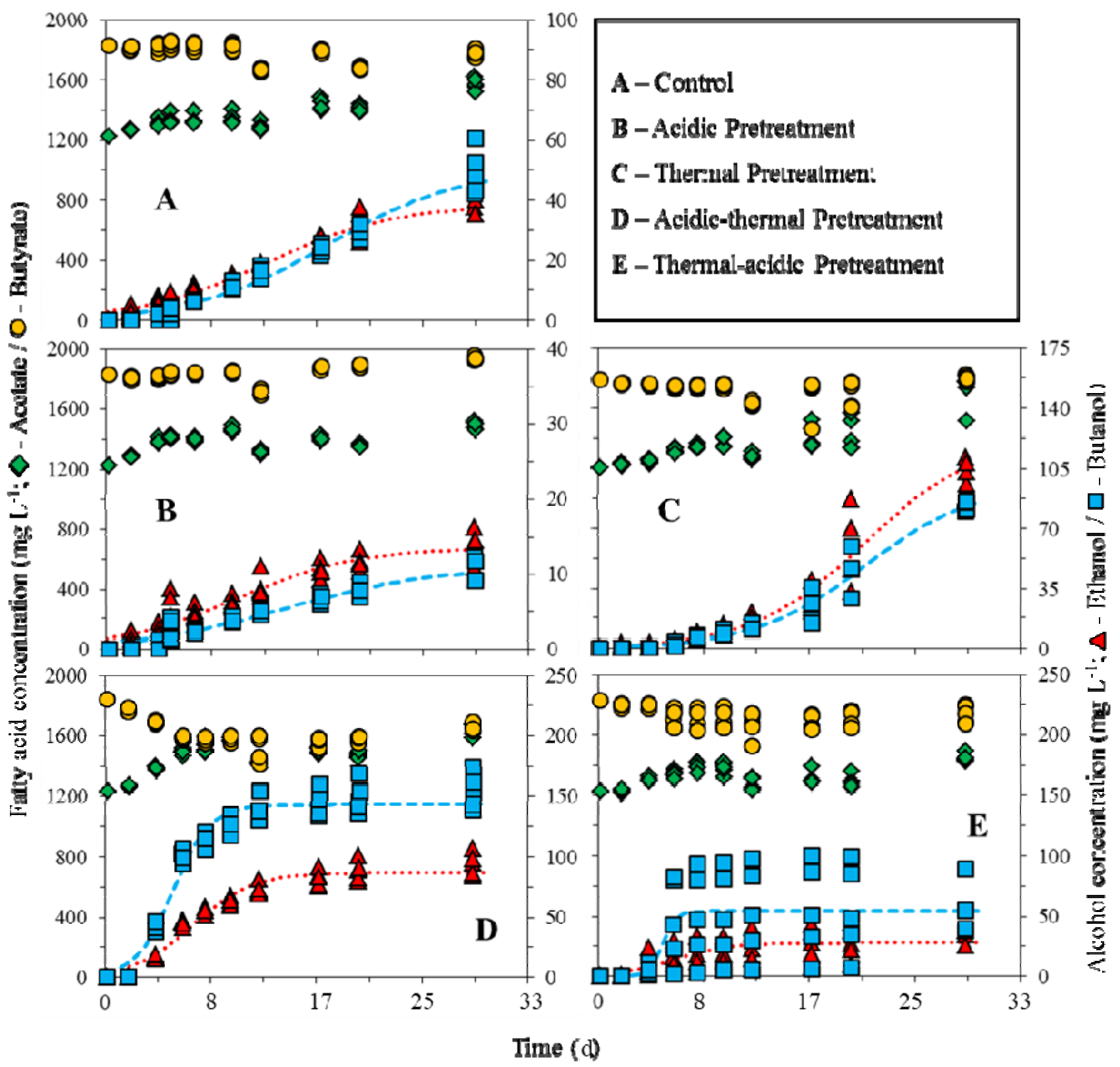

Figure 4 - Kinetics of VFAs (acetate and butyrate) and alcohols (ethanol and butanol) productions for 314 each studied condition. Red dotted- and blue dashed-lines represent the modified Boltzmann model 315 fittings for ethanol and butanol concentrations, respectively. 


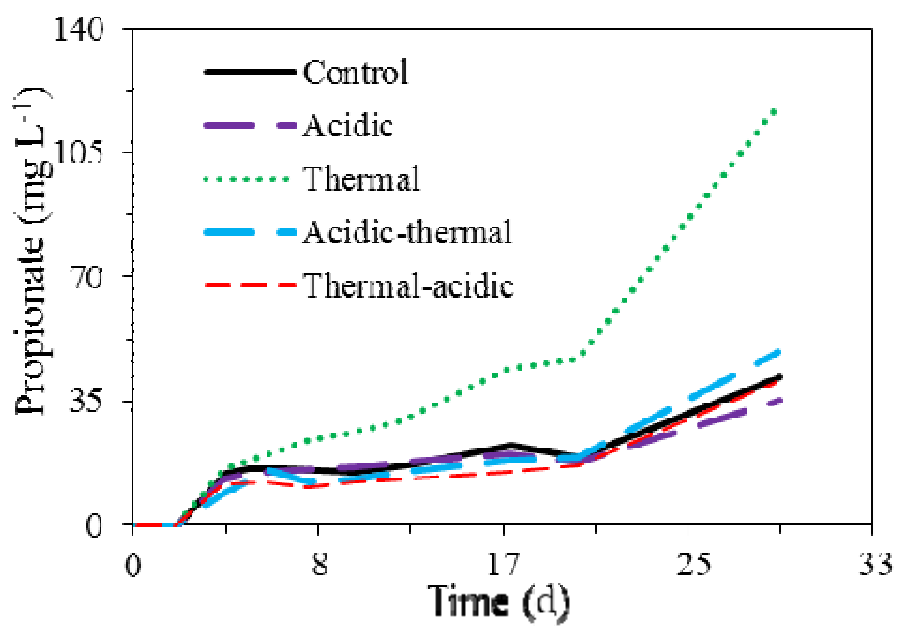

318 Figure 5 - Behaviour of propionate concentration for each studied condition.

320 As shown in Figure 5, propionate was produced in all conditions tested. No significant difference was 321 observed in the concentrations produced $\left(42.4 \pm 10.0 \mathrm{mg} \mathrm{L}^{-1}\right)$, except for the thermal pretreatment 322 essay, for which the level of production was 2.5 times higher than in all other conditions. As presented 323 in Table 3, propionate was then consumed and converted into propanol (pathway 5, Figure 1) for the 324 acidic, acidic-thermal and thermal-acidic pretreatments. Despite the favourable thermodynamics of this reaction (Figure 2), propanol was only produced in trace amounts. Oxidation of propionate into acetate was considered unlikely since such reaction is energetically unfeasible in standard conditions $\left(\Delta \mathrm{G}_{\mathrm{r}}^{\mathrm{o}}=\right.$ $53.3 \mathrm{~kJ} \mathrm{~mol}^{-1}$ ), and that, as previously described [39], at high $\mathrm{H}_{2}$ concentrations $\Delta \mathrm{G}_{\mathrm{r}}$ values are increased.

Table 5 presents the parameters of the modified Boltzmann model fitting the experimental data from

330 Figure 4. Those parameters are related to the kinetics of alcohol production and compare efficiencies 331 between all pretreatments. A high correspondence was obtained between replicates for all conditions 332 tested, apart from the thermal-acidic pretreatment. The correlation coefficient was very low in that condition, only reaching 0.5 for ethanol and 0.4 for butanol, indicating that the process was 
334 unpredictable and could not be reproduced. Due to its instability and unpredictability, the thermal335 acidic pretreatment was thus no longer considered for analyses.

336 Table 5 - Parameters of the modified Boltzmann model fitting for ethanol and butanol production.

\begin{tabular}{|c|c|c|c|c|c|c|}
\hline & \multirow{2}{*}{ Parameters } & \multicolumn{5}{|c|}{ Pretreatment of the inoculum } \\
\hline & & Control & Acidic & Thermal & Acidic-thermal & Thermal-acidic \\
\hline \multirow{6}{*}{$\begin{array}{l}\bar{O} \\
\text { 志 } \\
\text { 志 }\end{array}$} & $C_{\max }\left(\mathrm{mg} \mathrm{L}^{-1}\right)$ & $38.5 \pm 1.5$ & $13.6 \pm 0.7$ & $122 \pm 10$ & $87.3 \pm 1.9$ & $27.6 \pm 2.8$ \\
\hline & $t_{m}(\mathrm{~d})$ & $12.7 \pm 0.6$ & $10.4 \pm 0.8$ & $21.0 \pm 1.1$ & $6.9 \pm 0.3$ & $6.1 \pm 1.0$ \\
\hline & $r_{\max }\left(\mathrm{mg} \mathrm{L}^{-1} \mathrm{~d}^{-1}\right)$ & $1.9 \pm 0.0$ & $0.7 \pm 0.0$ & $7.0 \pm 0.48$ & $9.4 \pm 0.7$ & $3.1 \pm 1.2$ \\
\hline & $\mathrm{R}^{2}$ & 0.96 & 0.89 & 0.94 & 0.95 & 0.50 \\
\hline & $t_{i}(\mathrm{~d})$ & 2.7 & 0.9 & 12 & 2.3 & 1.6 \\
\hline & $t_{e}(\mathrm{~d})$ & 20 & 19 & 18 & 9.3 & 9.0 \\
\hline \multirow{6}{*}{ 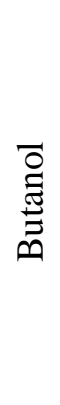 } & $C_{\max }\left(\mathrm{mg} \mathrm{L}^{-1}\right)$ & $50.7 \pm 2.3$ & $10.9 \pm 0.5$ & $96.7 \pm 6.8$ & $143 \pm 2$ & $53.8 \pm 5.4$ \\
\hline & $t_{m}(\mathrm{~d})$ & $17.6 \pm 0.7$ & $14.2 \pm 0.8$ & $21.1 \pm 1.0$ & $5.3 \pm 0.2$ & $5.1 \pm 0.8$ \\
\hline & $r_{\max }\left(\mathrm{mg} \mathrm{L}^{-1} \mathrm{~d}^{-1}\right)$ & $2.4 \pm 0.0$ & $0.5 \pm 0.0$ & $5.5 \pm 0.5$ & $25 \pm 2$ & $26 \pm 23$ \\
\hline & $\mathrm{R}^{2}$ & 0.97 & 0.94 & 0.96 & 0.96 & 0.40 \\
\hline & $t_{i}(\mathrm{~d})$ & 7.0 & 2.9 & 12 & 2.4 & 4.1 \\
\hline & $t_{e}(\mathrm{~d})$ & 21 & 23 & 18 & 6 & 2 \\
\hline
\end{tabular}

$C_{\text {max }}$, maximum concentration; $t_{m}$, time when maximum production rate is achieved; $r_{\text {max }}$, maximum production rate; $\mathrm{R}^{2}$, correlation coefficient; $t_{i}$ and $t_{e}$, initial and ending time of exponential growth phase.

338 As shown in Figure 4 and Table 5, both alcohol production and maximum production rates $\left(r_{\text {max }}\right)$ were 339 improved for thermal and acidic-thermal pretreatments. Although the highest ethanol production was 340 observed for the thermal pretreatment, the best results were obtained for the acidic-thermal 341 pretreatment, which allowed the best butanol production and an increase of 4.5 times of the ethanol and 342 of 10.2 times of the butanol maximum production rate. In opposition, a decrease in alcohol production 343 was observed for the acidic pretreatment. Such results clearly indicate that an acidic-thermal 344 pretreatment of the inoculum is a promising approach for designing more efficient and smaller-sized 345 bioreactors. 
346 Length of the lag phase $\left(t_{i}\right)$ and duration of the bacterial exponential growth phase $\left(t_{e}\right)$ were evaluated

347 for each pretreatment and compared to the control by considering alcohol production curves as growth348 associated curves (Table 3). The length of the lag phase is related to the time required for a bioreactor 349 to initiate its process (start-up) and achieve higher rates of alcohol production. For both ethanol and 350 butanol production, the shortest lag phases were observed for the acidic and acidic-thermal 351 pretreatments. In both pretreatments, the lag phase was shorter than found in the control essay. The 352 most extended lag phase was observed for the thermal pretreatment, which was considerably greater for 353 both ethanol and butanol production than observed in control. Such results indicate that the thermal 354 pretreatment had the highest impact on the inoculum, while acidic and acidic-thermal pretreatments 355 selected microbial communities which were the best adapted to solventogenic processes. Variations in 356 the duration of the bacterial exponential growth phases $\left(t_{e}\right)$ were also observed (Table 5). A shorter 357 exponential growth phase is representative of a faster process. However, this parameter must be 358 evaluated concomitantly with the maximum rates of production $\left(r_{\max }\right)$. For example, a short $t_{e}$ 359 occurring at low $r_{\text {max }}$ indicates a process occurring with low efficiency. Among all the conditions 360 tested, low $t_{e}$ values and high $r_{\max }$ values were obtained for the acidic-thermal pretreatment for 361 ethanol and butanol production. Taken all together, results obtained for all conditions tested indicate 362 that the acidic-thermal pretreatment was the best approach to generate a rapid and efficient process. 
363

364

365

366

367

368

369

370

371

372

373

374

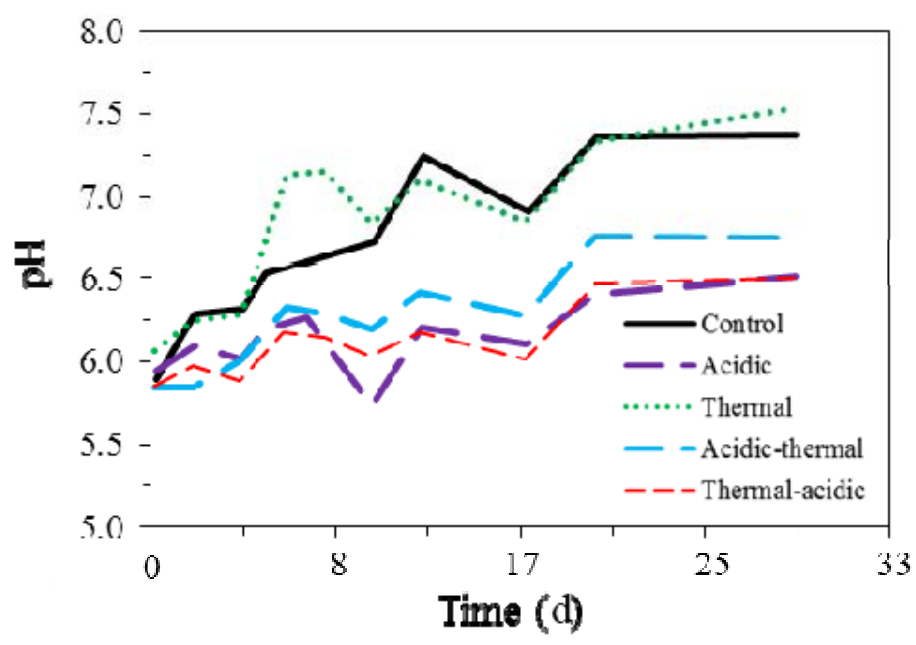

Figure 6 - Evolution of $\mathrm{pH}$ along the process for each studied condition.

$\mathrm{pH}$ was initially set to a value of $5.92 \pm 0.09$ for all essays, and their value increased during the experiments (Figure 6). This rise in $\mathrm{pH}$ values likely reflects the consumption of $\mathrm{H} 2$ as an electron donor to form alcohols since solventogenic pathways $(3,5$ and 6) require the consumption of $\mathrm{H}+$ and alcohols show a low ionization on water. Such a $\mathrm{pH}$ increase occurred to a lesser extent in all conditions, including an inoculum acidic pretreatment (acidic, acidic-thermal and thermal-acidic pretreatments). This difference might be explained by a more drastic initial $\mathrm{pH}$ drop resulting from the acidic addition on these pretreatments, probably lowering the buffering capacity of the inoculum. This hypothesis is reinforced by the concentrations of dissolved $\mathrm{CO}_{2}$, which were higher for both control and thermal pretreatment than acidic and acidic-thermal pretreatments (Table 3). 


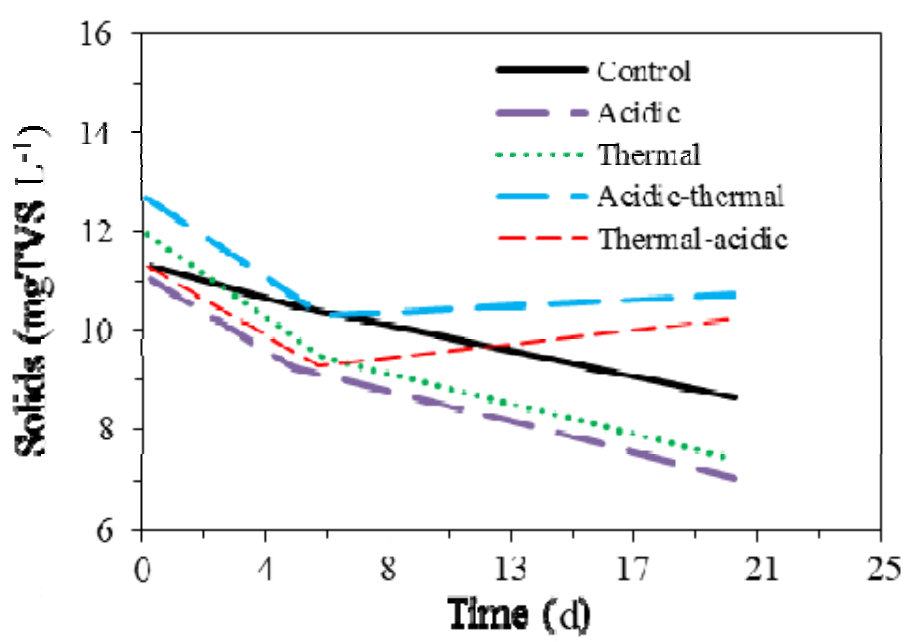

Figure 7 - Evolution of the total volatile solids (TVS) along the process for each studied condition.

A decrease in total volatile solids (TVS) was also observed for all conditions tested (Figure 7). This decrease occurred probably due to a direct effect of the different pretreatments on the biomass, resulting in partial microbial cell death. Such non-living cells constituted non-soluble organic matter which was probably hydrolyzed and then consumed as a carbon source, contributing to the organic matter input proposed in pathway 1 of Figure 1. The TVS concentration stopped decreasing and started to increase after 6.3 days in the acidic-thermal pretreatment slightly. Such evolution is probably linked to the higher values of observed for this pretreatment (Table 5), which reflect an increase in the biomass growth's rate, and consequently, the TVS concentration.

\subsection{Bacterial communities}

Based on the results presented above and focusing on alcohol production, both thermal and acidicthermal pretreatments experiments were submitted to microbial community analyses. Bacterial populations were thus characterized and monitored all along with those two processes. Thirteen phyla were detected, namely Firmicutes, Proteobacteria, Bacteroidetes, Actinobacteria, Synergistetes, Cyanobacteria, Tenericutes, Spirochaetes, Deinococcus-Thermus, Fibrobacteres, Verrucomicrobia, 
392 Chloroflexi and Nitrospirae. Among those, three (Firmicutes, Proteobacteria and Bacteroidetes) 393 represented up to $94.6 \%$ of the total OTUs detected in each sample for both pretreatments (Figure 8). 394 Firmicutes was the most abundant phylum detected in the initial non-treated inoculum (corresponding 395 to $66.6 \%$ of the detected OTUs). Both pretreatments generated a shift in the bacterial population by 396 stimulating the development of Proteobacteria and strongly reducing the number of Firmicutes. 397 Bacterial populations evolved differently along the process for the two pretreatments. In the thermal 398 pretreatment experiment (Figure 8A), a decrease of Proteobacteria was observed concomitantly with 399 an increase in Bacteroidetes and Firmicutes, the latest becoming the dominant phylum at the end of the 400 process. This shift started after 200 hours of experiment, which correspond to the early beginning of the 401 bacterial exponential growth phase (Figure 4C and Table 5). In opposition, in the acidic-thermal 402 pretreatment experiment (Figure 8B), relative stability was observed for the bacterial population, with 403 Proteobacteria remaining the main phylum all along the process $(72.0 \pm 4.99 \%$ of the detected OTUs) 404 and Firmicutes constantly being the second phylum of importance $(24.0 \pm 5.10 \%$ of the detected 405 OTUs). Bacteroidetes increased during the process, before starting to decrease after 500h of 406 experiment, to reach their initial level at the end of the experiment. 
407

408

409

410

412

414

415

416

411 Deeper phylogenetic analyses were performed down to the genus level to infer the potential metabolic
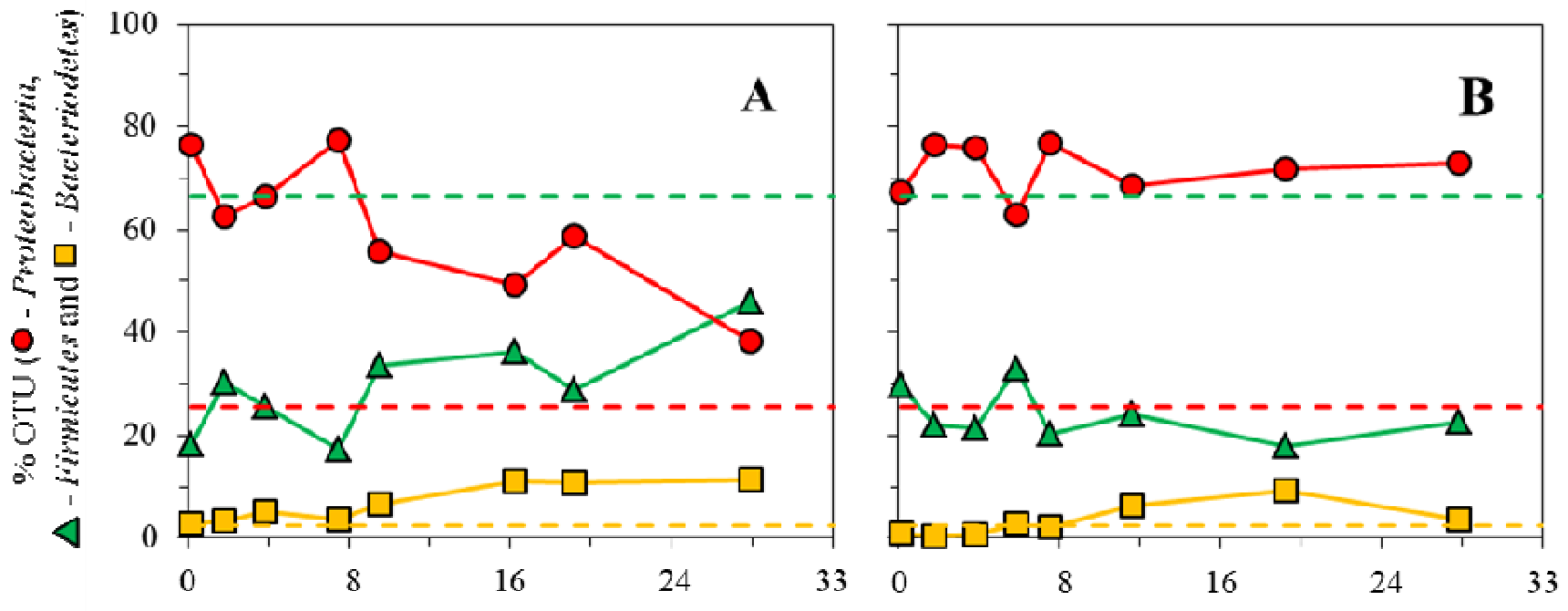

Time (d)

Figure 8 - Evolution of the three most representative bacterial phyla for the thermal (A) and acidicthermal (B) pretreatments. Dashed lines represent OTUs associated to those same phyla found in the inoculum without pretreatment. pathway(s) that could be associated with the enhancement of alcohol production observed for both thermal and acidic-thermal pretreatments (Figure 9). Substantial differences were noticed between the bacterial population from the initial inoculum (before any pretreatment) and those from the thermal and acidic-thermal pretreated inocula. 
bioRxiv preprint doi: https://doi.org/10.1101/2021.03.23.436570; this version posted May 12, 2021. The copyright holder for this preprint (which

was not certified by peer review) is the author/funder, who has granted bioRxiv a license to display the preprint in perpetuity. It is made available under aCC-BY-NC-ND 4.0 International license.
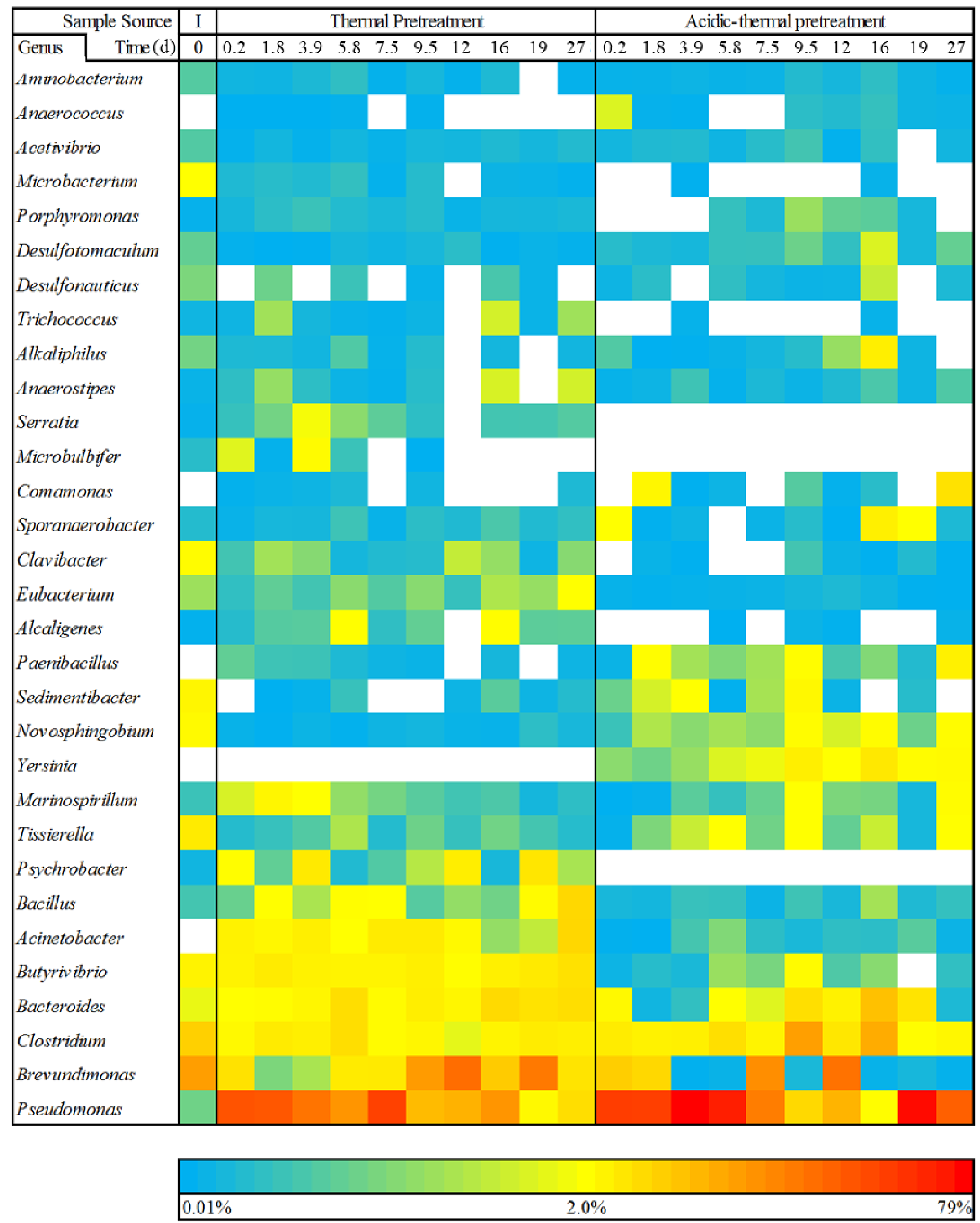

418 Figure 9 - Evolution of the bacterial population at the genus taxonomic level for thermal and acidic419 thermal pretreatments, and comparison with the initial bacterial population (I) for the 31 most detected 420 genera. 
422 A total of 317 genera were detected in all samples tested, but only 31 of them, representing up to $85 \%$ 423 of the bacterial population, were considered for further analysis (Figure 9). One of the most noticeable 424 changes consisted of an increase of Pseudomonas in pretreatment experiments compared to the initial 425 population. Such increase was observed as soon as the first hours of experiments. Pseudomonas then 426 remained a dominant genus of the bacterial population, despite a slight decrease observed for the 427 thermal pretreatment in the second half of the process. Several Pseudomonas species have been 428 genetically well-characterized and have been shown to possess the genetic components for both ethanol 429 (from pyruvate) and butanol (from glycerol and pyruvate) production [42]. The prevalence of 430 Pseudomonas is likely linked with the higher levels of alcohol production observed in thermal and 431 acidic-thermal pretreatments. Some Pseudomonas species also possess genes responsible for the 432 degradation of ethanol into acetyl-CoA [42]. A pathway related to ethanol degradation might explain 433 better butanol production compared to ethanol, observed for the acidic-thermal pretreatment. Among 434 the other noticeable results, two bacterial genera, namely Acinetobacter and Paenibacilus, which were 435 not detected in the initial population, appeared to be positively affected by both pretreatments. It is 436 being reported $[43,44]$ that Acinetobacter strains are related to alcohol consumption as they can express 437 alcohol dehydrogenase (ADH) to convert ethanol into acetate, reverting the solventogenic pathway 6. 438 As shown in Figure 2, this reversed pathway probably not occurred during the essays since in all 439 experiments, in their beginning and ending, $\Delta \mathrm{G}_{\mathrm{r}}$ for pathway 6 were thermodynamically feasible.

440 Conversely, $\mathrm{ADH}$ is also a molecule that is strongly related to bacterial quorum sensing with a key role 441 in biofilm formation [44,45]. The growth of Acinetobacter was more stimulated in the thermal 442 pretreatment, so this quorum sense mechanism could be linked with the best performance of this 443 pretreatment to produce alcohols, considering that the presence of ethanol could have stimulated the 444 expression of $\mathrm{ADH}$, although the alcohol degradation metabolism was probably shut down. Acidic- 
445 thermal pretreatment preferentially stimulated the growth of Paenibacilus, which is directly related to 446 alcohol production [46].

447 In addition to those changes, several other bacterial genera evolved differently depending on the 448 pretreatment applied (Figure 9). The thermal pretreatment appeared to stimulate the growth of 449 Brevundimonas, Bacteroides, Butyrivibrio, Bacillus, Alcaligenes, Eubacterium, Clavibacter, 450 Psychrobacter, Serratia and Microbulbifer. The latter three being even exclusively detected in this 451 pretreatment. On the opposite, the acidic-thermal pretreatment appeared to improve the growth of 452 Tissierella, Novosphingobium, Sedimentibacter and Yersinia. The latter one being exclusively detected 453 in this pretreatment.

454 The genus Brevudimonas started to increase in the thermal pretreatment after 8.3 days, coinciding with 455 the very beginning of the exponential growth phase (Figure 4 and Table 5). Members belonging to this 456 genus have already been shown to possess metabolic pathways related to the acidogenesis of alcohols 457 [47]. High $\mathrm{H}_{2}$ partial pressures applied during the process might have rendered solventogenesis 458 thermodynamically favourable through the reverse same metabolic pathway (Figure 3). The genus 459 Yersinia started to increase in the acidic-thermal pretreatment after approximately 4.2 days, coinciding 460 with the early exponential growth phase (Figure 4 and Table 5). Members belonging to this genus have 461 already been shown to possess metabolic pathways to convert pyruvate into butanol and ethanol [48]. 462 The genus Sedimentibacter is one of the predominant genus found in the fermentation of Baijiu, and it 463 could be directly related to alcohol production [49]. It is noticeable that the genus Clostridium, which is 464 composed of a high number of known alcohol producers [15,50-52], was detected for both 465 pretreatments all along the process, without any significant variations. The genus Clostridium usually 466 produces alcohol by converting glycerol and pyruvate into ethanol and butanol. Thus, this genus 467 probably has an essential role in producing ethanol and butanol in both thermal and acidic-thermal 
pretreatments. There is no reporting on alcohol-producing metabolism for all other genera found within

469 the experiments.

470 Other results were observed at higher taxonomic levels, notably decreasing microorganisms from the 471 Peptostreptococcaceae family and the Epsilonproteobacteria class, in both pretreatments. 472 Peptostreptococcaceae family represented almost half (45\% of total bacterial OTUs) found in the 473 initial inoculum (before any pretreatment), strongly decreased its presence to $5.4 \pm 2.2 \%$ in thermal and $4749.2 \pm 3.1 \%$ in acidic-thermal pretreatments. Epsilonproteobacteria class represented up to $6 \%$ of total 475 bacterial OTUs in the initial inoculum but significantly decreased to less than $0.3 \%$ of total bacterial 476 OTUs in both thermal and acidic-thermal pretreatments. Such results indicate that neither bacteria from 477 the Peptostreptococcaceae family nor Epsilonproteobacteria class played a significant role in the 478 processes studied.

\section{Conclusions}

480 Characterization of the initial microbial population showed the presence of bacteria possessing 481 metabolic pathways for alcohol production. Both thermal and acidic-thermal pretreatments were able to 482 select the best adapted bacterial communities to produce ethanol and butanol. The significant decrease 483 of members belonging to the family Peptostreptococaceae coupled to an increase of Pseudomonas 484 appeared to be related to the best performance of ethanol and butanol production. The acidic-thermal 485 pretreatment generated the best results, reaching a concentration of $87 \mathrm{mg} \mathrm{L}^{-1}$ of ethanol and of $143 \mathrm{mg}$ $\mathrm{L}^{-1}$ of butanol after 240 hours of processing. The thermal pretreatment achieved the highest ethanol 487 production $\left(122 \mathrm{mg} \mathrm{L}^{-1}\right)$ but at a much slower rate (after 710 hours). The two other pretreatments 488 studied showed either instability and inconsistency for the thermal-acidic pretreatment or very low 489 alcohol production for the acidic pretreatment. Among the VFAs added to the medium, butyrate was 490 used solely as the substrate, acetate being produced along the process. The mass balance study 
bioRxiv preprint doi: https://doi.org/10.1101/2021.03.23.436570; this version posted May 12, 2021. The copyright holder for this preprint (which

was not certified by peer review) is the author/funder, who has granted bioRxiv a license to display the preprint in perpetuity. It is made available under aCC-BY-NC-ND 4.0 International license.

491 highlighted another substrate input, which was probably originating from the inoculum. 492 Thermodynamic data indicated that homoacetogenesis was a critical pathway to produce acetate from 493 dissolved $\mathrm{CO}_{2}$ and $\mathrm{H}_{2}$. Finally, $\mathrm{H}_{2}$ partial pressure was a preponderant factor for solventogenesis, 494 enabling alcohol production and inhibiting its consumption. 
4957 List of Abbreviations Used

496 STP

$497 \quad \mathrm{ppH}_{2}$

$498 \quad \mathrm{R}^{2}$

499 TVS

500 OTU

501 HPLC

502 PCR

503 RDP

504 VFA

$505 \mathrm{But}^{-}$

506 Prop $^{-}$

$507 \mathrm{Ac}^{-}$

$508 \operatorname{But}(\mathrm{OH})$

$509 \operatorname{Prop}(\mathrm{OH})$

510 Eth $(\mathrm{OH})$

$511 C(t)$

$512 t$

$513 t_{i}$

$514 t_{e}$

$515 t_{m}$

$516 r_{\max }$

$517 C_{\max }$

$518 \Delta \mathrm{G}_{\mathrm{r}}$

$519 \Delta \mathrm{G}_{\mathrm{r}}^{\circ}$

$520 \Delta \mathrm{G}_{\mathrm{r}}^{\mathrm{F}}$

$521 \Delta \mathrm{G}_{\mathrm{r}}^{\mathrm{I}}$
Standard temperature and pressure $\left(0^{\circ} \mathrm{C}\right.$ and $\left.1 \mathrm{~atm}\right)$;

Partial $\mathrm{H}_{2}$ pressure (atm);

Levenberg-Marquardt algorithm correlation coefficient;

Total volatile solids $\left(\mathrm{mg} \mathrm{L}^{-1}\right)$;

Operational taxonomic unit;

High performance liquid chromatography;

Polymerase chain reaction;

Ribosomal data project;

Volatile fatty acid;

Butyrate;

Propionate;

Acetate;

Butanol;

Propanol;

Ethanol;

Concentration in respect of time $\left(\mathrm{mg} \mathrm{L}^{-1}\right)$;

Time (h);

Initial time for exponential growth phase (h);

Ending time for exponential growth phase (h);

Time in which maximum production rate $\left(r_{\max }\right)$ is achieved $(\mathrm{h})$;

Maximum production rate $\left(\mathrm{mg} \mathrm{L}^{-1} \mathrm{~h}^{-1}\right)$;

Maximum concentration $\left(\mathrm{mg} \mathrm{L}^{-1}\right)$;

Variation of Gibbs' free energy at a given condition $\left(\mathrm{kJ} \mathrm{mol}^{-1}\right)$;

Variation of Gibbs' free energy at standard condition $\left(\mathrm{kJ} \mathrm{mol}^{-1}\right)$;

Variation of Gibbs' free energy at final experiment condition $\left(\mathrm{kJ} \mathrm{mol}^{-1}\right)$;

Variation of Gibbs' free energy at initial experiment condition $\left(\mathrm{kJ} \mathrm{mol}^{-1}\right)$. 


\section{Competing Interests}

523 The authors declare that they have no competing interests.

\section{Authors' Contribution}

525 All authors have planned the experiments. GM performed all the experiments, data treatment, statistics, 526 and mathematical modeling. GB treated and analysed all sequencing data. All authors have analysed 527 and discussed the results. GM have written the paper. All authors have read, reviewed, and approved 528 the final manuscript. Experiments were conducted in Montréal branch of National Research Council of 529 Canada from January to July of 2014.

\section{Authors' Informations}

$531 \mathrm{GM}$ is professor of sanitation and applied microbiology of the Agricultural Engineering College at 532 Campinas State University (FEAGRI/UNICAMP). This research was developed as an invited 533 researcher at National Research Council of Canada (NRC) from October/2013 to October/2014, under 534 a post-doctoral program in biofuels in the São Carlos Engineering School at University of São Paulo 535 (EESC/USP).

\section{Acknowledgements}

537 This work was supported by FAPESP - Fundação de Amparo a Pesquisa do Estado de São Paulo 538 (processes 2010/18.463-9 and 2013/18.172-2 - G. Mockaitis and 2009/15.984-0 - M. Zaiat), and the 539 NRC - National Research Council of Canada (project A1-004645 - S.R. Guiot).

540 The authors thankfully acknowledge Marie-Josée Lévesque, Christine Maynard and Sylvie Sanschagrin 541 for their assistance with the biomolecular techniques (DNA extraction, purification and PCR) and 542 sequencing (through Ion Torrent ${ }^{\mathrm{TM}}$ ); and also, Stephane Deschamps and Alain Corriveau for their 543 valuable contribution with physicochemical analysis (HPLC and gas chromatography of alcohols). 


\section{References}

545

546

547

548

549

550

551

552

553

554

555

556

557

558

559

560

561

562

563

564

565

566

567

568

569

570

571

572

573

574

575

576

577

578

579

580

581

582

583

584

585

[1] Jones DT, Woods DR. Acetone-butanol fermentation revisited. Microbiol Rev 1986;50:484524.

[2] Das D, Veziroglu T. Advances in biological hydrogen production processes. Int J Hydrogen Energy 2008;33:6046-57. https://doi.org/10.1016/j.ijhydene.2008.07.098.

[3] Baumann I, Westermann P. Microbial Production of Short Chain Fatty Acids from Lignocellulosic Biomass: Current Processes and Market. Biomed Res Int 2016;2016. https://doi.org/10.1155/2016/8469357.

[4] Levin D. Biohydrogen production: prospects and limitations to practical application. Int J Hydrogen Energy 2004;29:173-85. https://doi.org/10.1016/S0360-3199(03)00094-6.

[5] Steinbusch KJJ, Hamelers HVM, Buisman CJN. Alcohol production through volatile fatty acids reduction with hydrogen as electron donor by mixed cultures. Water Res 2008;42:4059-66. https://doi.org/10.1016/j.watres.2008.05.032.

[6] Zverlov V V, Berezina O, Velikodvorskaya G a, Schwarz WH. Bacterial acetone and butanol production by industrial fermentation in the Soviet Union: use of hydrolyzed agricultural waste for biorefinery. Appl Microbiol Biotechnol 2006;71:587-97. https://doi.org/10.1007/s00253006-0445-z.

[7] Agler MT, Wrenn B a, Zinder SH, Angenent LT. Waste to bioproduct conversion with undefined mixed cultures: the carboxylate platform. Trends Biotechnol 2011;29:70-8. https://doi.org/10.1016/j.tibtech.2010.11.006.

[8] Dürre P. New insights and novel developments in clostridial acetone/butanol/isopropanol fermentation. Appl Microbiol Biotechnol 1998:639-48.

[9] Brynjarsdottir H, Wawiernia B, Orlygsson J. Ethanol Production from Sugars and Complex Biomass by Thermoanaerobacter AK 5 $\square$ : The Effect of Electron-Scavenging Systems on EndProduct Formation. Energy and Fuels 2012;26:4568-74.

[10] Jessen JE, Orlygsson J. Production of ethanol from sugars and lignocellulosic biomass by Thermoanaerobacter $\mathrm{J} 1$ isolated from a hot spring in Iceland. $\mathbf{J}$ Biomed Biotechnol 2012;2012:186982. https://doi.org/10.1155/2012/186982.

[11] Almarsdottir AR, Sigurbjornsdottir MA, Orlygsson J. Effect of various factors on ethanol yields from lignocellulosic biomass by Thermoanaerobacterium AK $\square \square$. Biotechnol Bioeng 2012;109:686-94. https://doi.org/10.1002/bit.24346.

[12] Crespo CF, Badshah M, Alvarez MT, Mattiasson B. Ethanol production by continuous fermentation of D-(+)-cellobiose, D-(+)-xylose and sugarcane bagasse hydrolysate using the thermoanaerobe Caloramator boliviensis. Bioresour Technol 2012;103:186-91. https://doi.org/10.1016/j.biortech.2011.10.020.

[13] Xu L, Tschirner U. Improved ethanol production from various carbohydrates through anaerobic thermophilic co-culture. Bioresour Technol 2011;102:10065-71. https://doi.org/10.1016/j.biortech.2011.08.067.

[14] Mes-Hartree M, Saddler J. Butanol production of Clostridium acetobutylicum grown on sugars found in hemicellulose hydrolysates. Biotechnol Lett 1982;4:247-52.

[15] Maddox I. Production of ethanol and n-butanol from hexose/pentose mixtures using consecutive fermentations with Saccharomyces cerevisiae and Clostridium acetobutylicum. Biotechnol Lett 
1982;4:23-8.

[16] Ounine K, Petitdemange H, Raval G, Gay R. Acetone-butanol production from pentoses by Clostridium acetobutylicum. Biotechnol Lett 1983;5:605-10.

[17] Li Z, Shi Z, Li X. Models construction for acetone-butanol-ethanol fermentations with acetate/butyrate consecutively feeding by graph theory. Bioresour Technol 2014;159:320-6. https://doi.org/10.1016/j.biortech.2014.02.095.

[18] Kumar M, Goyal Y, Sarkar A, Gayen K. Comparative economic assessment of ABE fermentation based on cellulosic and non-cellulosic feedstocks. Appl Energy 2012;93:193-204. https://doi.org/10.1016/j.apenergy.2011.12.079.

[19] Kleerebezem R, van Loosdrecht MCM. Mixed culture biotechnology for bioenergy production. Curr Opin Biotechnol 2007;18:207-12. https://doi.org/10.1016/j.copbio.2007.05.001.

[20] Puig S, Coma M, Monclús H, van Loosdrecht MCM, Colprim J, Balaguer MD. Selection between alcohols and volatile fatty acids as external carbon sources for EBPR. Water Res 2008;42:557-66. https://doi.org/10.1016/j.watres.2007.07.050.

[21] O-Thong S, Prasertsan P, Birkeland N-K. Evaluation of methods for preparing hydrogenproducing seed inocula under thermophilic condition by process performance and microbial community analysis. Bioresour Technol 2009;100:909-18. https://doi.org/10.1016/j.biortech.2008.07.036.

[22] Luo G, Karakashev D, Xie L, Zhou Q, Angelidaki I. Long-term effect of inoculum pretreatment on fermentative hydrogen production by repeated batch cultivations: homoacetogenesis and methanogenesis as competitors to hydrogen production. Biotechnol Bioeng 2011;108:1816-27. https://doi.org/10.1002/bit.23122.

[23] Pendyala B, Chaganti SR, Lalman J a., Shanmugam SR, Heath DD, Lau PCK. Pretreating mixed anaerobic communities from different sources: Correlating the hydrogen yield with hydrogenase activity and microbial diversity. Int J Hydrogen Energy 2012;37:12175-86. https://doi.org/10.1016/j.ijhydene.2012.05.105.

[24] Kumar M, Gayen K, Saini S. Role of extracellular cues to trigger the metabolic phase shifting from acidogenesis to solventogenesis in Clostridium acetobutylicum. Bioresour Technol 2013;138:55-62. https://doi.org/10.1016/j.biortech.2013.03.159.

[25] Angelidaki I, Petersen SP, Ahring BK. Applied Microbiolog . v Effects of lipids on thermophilic anaerobic digestion and reduction of lipid inhibition upon addition of bentonite 1990:469-72.

[26] Sander R. Compilation of Henry' s Law Constants for Inorganic and Organic Species of Potential Importance in Environmental Chemistry 1999.

[27] Lide DR, Frederikse HPR, editors. CRC Handbook of Chemistry and Physics. 76th ed. Boca Ratón, FL, USA: CRC Press Inc.; 1995.

[28] APHA. Standard methods for the examination of water and wastewater. 21st ed. Washington DC: 2005.

[29] Dilallo R, Albertson O. Volatile Acids by Direct Titration. J Water Pollut Control Fed 1961;33:356-65.

[30] Ripley L, Boyle W, Convrese J. Improved alkalimetric monitoring for anaerobic digestion of high-strength wastes. J Water Pollut Control Fed 1986;58:406-11.

[31] Guiot SR, Cimpoia R, Carayon G. Potential of wastewater-treating anaerobic granules for biomethanation of synthesis gas. Environ Sci Technol 2011;45:2006-12. 
https://doi.org/10.1021/es102728m.

[32] Muyzer G, Dewaal EC, Uitterlinden AG. Profiling of complex microbial populations by desnaturing gradient gel electrophoresis analysis ofpolymerase chain reaction amplified genes coding for 16S ribosomal RNA. Appl Environ Microbiol 1993;59:695-700.

[33] Griffiths RI, Whiteley a S, O'Donnell a G, Bailey MJ. Rapid method for coextraction of DNA and RNA from natural environments for analysis of ribosomal DNA- and rRNA-based microbial community composition. Appl Environ Microbiol 2000;66:5488-91.

[34] Lévesque MJ, La Boissière S, Thomas JC, Beaudet R, Villemur R. Rapid method for detecting Desulfitobacterium frappieri strain PCP-1 in soil by the polymerase chain reaction. Appl Microbiol Biotechnol 1997;47:719-25.

[35] Berthelet M, Whyte LG, Greer CW. Rapid, direct extraction of DNA from soils for PCR analysis using polyvinylpolypyrrolidone spin columns. FEMS Microbiol Lett 1996;138:17-22.

[36] Wang Q, Garrity GM, Tiedje JM, Cole JR. Naive Bayesian classifier for rapid assignment of rRNA sequences into the new bacterial taxonomy. Appl Environ Microbiol 2007;73:5261-7. https://doi.org/10.1128/AEM.00062-07.

[37] Claesson MJ, O'Sullivan O, Wang Q, Nikkilä J, Marchesi JR, Smidt H, et al. Comparative analysis of pyrosequencing and a phylogenetic microarray for exploring microbial community structures in the human distal intestine. PLoS One 2009;4:e6669. https://doi.org/10.1371/journal.pone.0006669.

[38] Mavrovouniotis ML. Group contributions for estimating standard gibbs energies of formation of biochemical compounds in aqueous solution. Biotechnol Bioeng 1990;36:1070-82. https://doi.org/10.1002/bit.260361013.

[39] Mavrovouniotis ML. Errata Group Contributions for Estimating Standard Gibbs Energies of Formation of Biochemical Compounds in Aqueous Solution 1991;38:803-4.

[40] Harper SR, Pohland FG. Recent Developments in Hydrogen Management During Anaerobic Biological Wastewater Treatment. Biotechnol Bioeng 1985;28:585-602.

[41] Speece RE. Anaerobic biotechnology for industrial wastewater. Vanderbilt University; 1996.

[42] Caspi R, Billington R, Fulcher CA, Keseler IM, Kothari A, Krummenacker M, et al. The MetaCyc database of metabolic pathways and enzymes. Nucleic Acids Res 2018;46:D633-9. https://doi.org/10.1093/nar/gkx935.

[43] John J, Saranathan R, Adigopula LN, Thamodharan V, Singh SP, Pragna Lakshmi T, et al. The quorum sensing molecule $\mathrm{N}$-acyl homoserine lactone produced by Acinetobacter baumannii displays antibacterial and anticancer properties. Biofouling 2016;32:1029-47. https://doi.org/10.1080/08927014.2016.1221946.

[44] Zhang K, Yang X, Yang J, Qiao X, Li F, Liu X, et al. Alcohol dehydrogenase modulates quorum sensing in biofilm formations of Acinetobacter baumannii. Microb Pathog 2020;148:104451. https://doi.org/10.1016/j.micpath.2020.104451.

[45] Subhadra B, Hwan Oh M, Hee Choi C. Quorum sensing in <em>Acinetobacter</em>: with special emphasis on antibiotic resistance, biofilm formation and quorum quenching. AIMS Microbiol 2016;2:27-41. https://doi.org/10.3934/microbiol.2016.1.27.

[46] Grady EN, MacDonald J, Liu L, Richman A, Yuan ZC. Current knowledge and perspectives of Paenibacillus: A review. Microb Cell Fact 2016;15:203. https://doi.org/10.1186/s12934-0160603-7. 
672

673

674

675

676

677

678

679

680

681

682

683

684

685

686

687

688

689

690

691

692

[47] Leifson E, Hugh R. A new type of polar monotrichous flagellation. J Gen Microbiol 1954;10:68-70. https://doi.org/10.1099/00221287-10-1-68.

[48] Caspi R, Altman T, Dale JM, Dreher K, Fulcher CA, Gilham F, et al. The MetaCyc database of metabolic pathways and enzymes and the BioCyc collection of pathway/genome databases. Nucleic Acids Res 2010;38:D473-9. https://doi.org/10.1093/nar/gkp875.

[49] Xu J, Sun L, Xing X, Sun Z, Gu H, Lu X, et al. Culturing Bacteria From Fermentation Pit Muds of Baijiu With Culturomics and Amplicon-Based Metagenomic Approaches. Front Microbiol 2020;11:1223. https://doi.org/10.3389/fmicb.2020.01223.

[50] Tracy BP, Jones SW, Fast AG, Indurthi DC, Papoutsakis ET. Clostridia: the importance of their exceptional substrate and metabolite diversity for biofuel and biorefinery applications. Curr Opin Biotechnol 2012;23:364-81. https://doi.org/10.1016/j.copbio.2011.10.008.

[51] Ueki A, Hirono T, Sato E, Mitani A, Ueki K. Ethanol and amylase production by a newly isolated Clostridium sp. World J Microbiol ... 1991;7:385-93.

[52] Bruant G, Lévesque M-J, Peter C, Guiot SR, Masson L. Genomic analysis of carbon monoxide utilization and butanol production by Clostridium carboxidivorans strain P7. PLoS One 2010;5:e13033. https://doi.org/10.1371/journal.pone.0013033.

\section{One-Sentence Summary}

The inoculum pretreatment acid and thermal improved significantly the production of both ethanol and butanol, through an anaerobic solventogenic process, using acetate and butyrate as carbon source and $\mathrm{H}_{2}$ as electron donor. 